\title{
SEISMIC POUNDING OF A CASE OF ADJACENT MULTIPLE-STOREY BUILDINGS OF DIFFERING TOTAL HEIGHTS CONSIDERING SOIL FLEXIBILITY EFFECTS
}

\author{
A.M. Rahman ${ }^{1}$, A.J. Carr ${ }^{2}$ and P.J. Moss ${ }^{2}$
}

\begin{abstract}
Collisions between adjacent structures due to insufficient separation gaps have been witnessed in almost every major earthquake since the 1960's. Although many analytical, numerical and experimental studies have been conducted into the pounding phenomenon, the number of those which take into account the effects of the underlying soil mass on the dynamic response of the colliding structures are almost negligible. The present study incorporates the effects of soil flexibility on the inelastic dynamic response of a particular case of adjacent 12- and 6-storey reinforced concrete moment-resisting frames. The timehistory response of this system (linear soil behaviour and nonlinear structural response) subjected to actual earthquake records is evaluated by means of the structural analysis software RUAUMOKO developed at the University of Canterbury. A simple mass-spring-dashpot model is used to represent the frequency independent dynamic soil properties. Impacts at storey levels only are considered.
\end{abstract}

This study highlights serious inconsistencies in the assumptions of previous pounding studies, which neglect the effects of soil flexibility. Also, the pounding response of the adjacent structures is found to be highly sensitive to the characteristics and direction of the seismic excitation.

\section{INTRODUCTION}

The disparity in the dynamic characteristics of adjacent structures leads to an out-of-phase oscillation of the structures when subjected to an external excitation. Impacts will occur if the separation gap between the structures is insufficient to accommodate the lateral displacements due to this out-of-phase oscillation. The magnitudes of the impact forces and the locations of impacts along the heights of the structures depend on the magnitude of the existing separation gap, the extent of the disparity between the dynamic properties of the impacting structures, and the characteristics of the excitation. It is therefore apparent that, under most conditions, the properties of the foundation soil must also be taken into consideration due to its influence on the above aspects.
Over the past 20 years, extensive analytical, numerical, and experimental studies have been conducted into the following aspects of the pounding phenomenon:

- Analytical and numerical modelling of the impact phenomenon [1-3].

- Development of mathematical expressions defining the optimum separation gap between adjacent buildings for implementation into seismic design codes [4-9].

- Quantification of the impact forces and their effects on the dynamic response of the impacting structures [1012].

\footnotetext{
${ }^{\prime}$ Formerly Department of Civil Engineering, University of Canterbury, Christchurch, New Zealand, currently Department of Applied Mechanics, Darmstadt Technical University, Germany, (Member).

${ }^{2}$ Department of Civil Engineering, University of Canterbury, Christchurch, New Zealand, (Fellow).
} 
- Means of mitigating the effects of pounding at the design stage or in existing buildings through mechanical devices or construction details [13-16].

- Case studies [17-21] and numerical investigations [2223] of observed occurrences of structural pounding.

However, only a small number of studies (see Section 3 ) have considered the effect of the supporting soil on the pounding response and none have included the influence of the adjacent structures on the dynamic response characteristics of the system. The purpose of the present study is the investigation of the influence of soil flexibility on the dynamic response of adjacent moment-resistant reinforced concrete frame structures subjected to pounding. The term "soil flexibility" used herein designates the effect of the soil properties on both the dynamic response characteristics of the individual oscillating systems (soil-structure interaction) and the through-soil interaction between the adjacent structures. A two-dimensional dynamic structural analysis software package developed at the University of Canterbury (RUAUMOKO [24]) is utilised to conduct the inelastic timehistory analyses. The reinforced concrete moment-resistant frames are designed in accordance with the relevant New Zealand codes $[25,26]$ and through-soil coupling and soilstructure interaction are simulated by appropriate discrete element (spring-mass-dashpot) systems. The frames are 12and 6-stories high with various magnitudes of initial separation gaps. Impacts at storey levels only were considered. The effect of various earthquake records on the pounding response is investigated by means of two earthquake accelerograms, the N-S component of the $1940 \mathrm{El}$ Centro earthquake and the Sylmar County Hospital accelerogram recorded during the 1994 Northridge Earthquake. In addition to the fifteen-second forced-vibration phase, a free-vibration phase of five-second duration is allowed at the termination of the seismic excitation. The effect of seismic attack from opposite directions is also investigated.

This study shows that certain basic assumptions implemented in previous pounding studies are not applicable when soil flexibility is taken into consideration. The results presented herein pertain only to those effects on the impact forces.

\section{REVIEW OF OBSERVED CASES OF STRUCTURAL POUNDING}

The first mention of structural pounding in the literature appears to have been in 1926 [27] in which the pounding of non-structural components against the structural elements of a building was discussed and the provision of a sufficient separation gap and proper detailing were recommended. Since then, the increase in urban development, and the associated increase in real-estate values, has compelled developers and designers to maximise land usage. This has led to the construction of many buildings up to their property lines in disregard of the recommendations of many seismic codes which stipulate the provision of a minimum separation distance between adjacent buildings.
Many cases of structural pounding witnessed during major seismic events in recent times have been described in the literature. The extent of damage resulting from structural pounding varied in the incidents reported from cosmetic or light [28] to severe [19] and in some cases ensued in total collapse $[17,18]$. In addition, the high-amplitude local accelerations induced by pounding pose a significant threat to the operation of appurtenances and sensitive equipment at the level of pounding [29].

Structural pounding may occur in parts of the same building such as at expansion or construction joints [22] or between non-structural and structural components [19]. Pedestrian bridges may also pose a potential pounding risk as they may collide against the structures which they connect as was witnessed during the Hyogo-ken-Nanbu (Kobe) earthquake of 1995 [28]. Substantial damage due to pounding may be sustained by adjacent buildings with differing storey heights (Figure 1). In this case, the column of one building may sustain repeated impacts along its height from the slab of the adjacent building resulting in localised damage of the column and possibly partial collapse of the storey [18].

Structural damage due to pounding has also been observed in bridges when the separation gap provided between the bridge segments [30] or between the bridge and its abutments [11] was exceeded. Inadequate separation gaps have been identified as the cause of base-isolated buildings pounding against their stops during the 1994 Northridge earthquake [31].

Although the Mexico City earthquake of 1985 is often cited as the most important single event in which extensive pounding damage was reported [32], the actual severity of the damage attributed directly to pounding may have been overstated [33]. Nonetheless, the potential structural and nonstructural damage due to pounding should be assessed, be it during the design stage or in the seismic assessment of structures. Ample provisions should be implemented to minimise the potential threat to human life (such as may be caused by falling debris, e.g. glass or concrete, or the loss of a structural element, e.g. failure of a column due to sustained pounding at its mid-height) and to limit the financial losses which the owner may incur.

\section{PREVIOUS POUNDING STUDIES INCORPORATING SOIL-STRUCTURE INTERACTION}

Although extensive efforts have been expended towards investigation of the pounding phenomenon from all aspects, the effects of soil conditions on the pounding response have been neglected. In order to facilitate the analytical and numerical representation and solution of the equations pertinent to the pounding phenomenon, conventional studies assume a fixed-base connection between the impacting structures and the supporting foundation soils in addition to neglecting the through-soil interaction between these structures. The former assumption implies a very stiff 
foundation soil. This may be true in the case of low structure mass to soil stiffness ratio but is not valid for cases of heavy structures constructed on soft soils. The neglect of throughsoil interaction implies the complete isolation of the oscillating structures from the soil environment in which they are constructed. Obviously this is a gross simplification as there is a significant degree of interaction between adjacent structures at foundation level due to the effects of the outward-propagating energy waves.

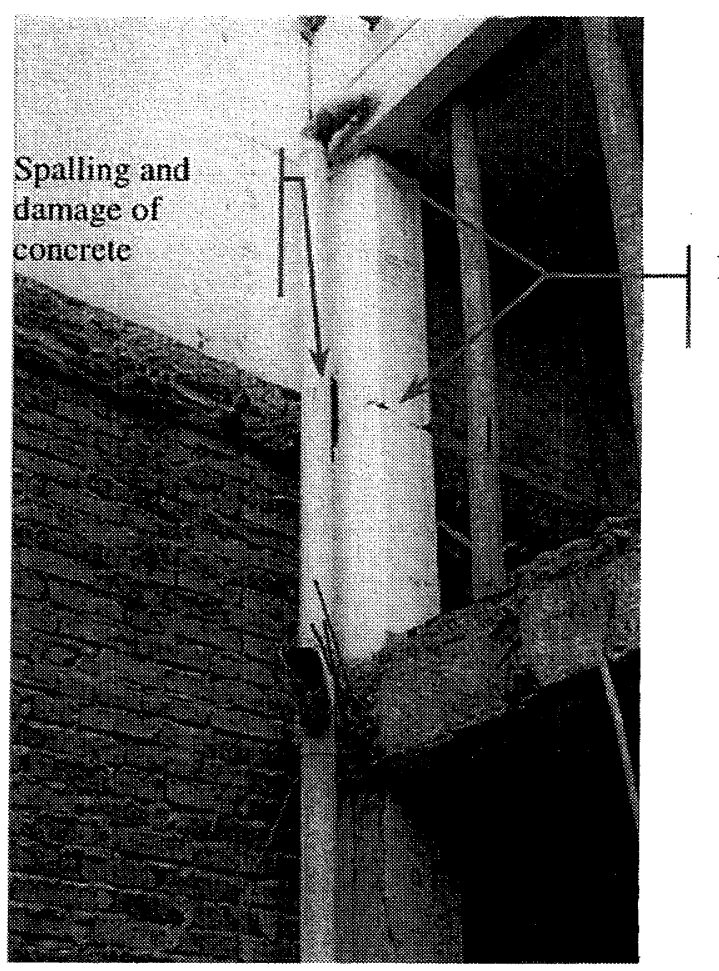

Figure 1: An example of pounding damage (slab to column) this one occurring during the 1999 Armenia (Columbia) Earthquake. (Photo courtesy of J. Restrepo).

To the authors' knowledge, the only study that specifically investigates the influence of soil-structure interaction on the pounding response is the analytical investigation conducted by Schmid and Chouw [34]. A boundary-element solution was applied in the modelling of the continuous half-space (soil mass) underlying the two buildings. While through-soil coupling was not considered, they concluded that soilstructure interaction effects had a profound influence on postimpact behaviour which cannot be extrapolated from an analysis assuming fixed-base conditions.

Anagnostopoulos and Spiliopoulos [10] modelled the supporting soil mass as a discrete element (spring-dashpot) system for the translational and rocking degrees-of-freedom. A five-fold reduction in the soil stiffness resulted in an increase in the natural periods of the oscillating systems and hence to a reduction of the displacement ductility demands of the impacting inelastic multi-degree-of-freedom systems and to a reduction of storey shears in the elastic analysis.
Kasai et al. [22], in their survey of structural pounding damage which occurred during the 1989 Loma Prieta earthquake, noted the correlation between the incidence of pounding and the soil conditions prevalent at these sites. They postulated that the increased intensity of shaking due to soft soil conditions and/or the possible occurrence of structural settlement and rocking at these sites might have been contributing factors to pounding.

Valles and Reinhorn [8] suggested a mathematical expression to determine the critical separation gap required to preclude pounding. In this equation, an expression accounting for foundation rotation due to soil-structure interaction effects was included.

\section{EFFECTS OF POUNDING ON DYNAMIC RESPONSE}

Impacts due to structural pounding transmit short duration, high amplitude forces to the impacting structures and may occur at any level of the colliding structures and at any location along the impacting levels (in the case of disparate storey heights of the adjacent buildings resulting in slabcolumn impacts). The detrimental effects of these forces may be enumerated as follows:

- High amplitude, short duration local accelerations.

- Localised degradation of stiffness, and/or strength in impacting members. In addition to the adverse effects this will entail on the strength of the members, the distribution of shear and flexural forces will also be affected. Since the design of earthquake resistant structures in most codes is based upon the capacity design method [35], this is an especially significant factor which must be accounted for when assuming plastic hinge locations (Figure 1)

- Modification to the overall dynamic response of structures. Either an amplification or de-amplification of response will be sustained by the structures, depending on the relative dynamic characteristics (mass and stiffness) of the impacting structures on one hand and the supporting medium on the other, in addition to the characteristics of the seismic excitation. Modes of response not accounted for in design may be introduced, for example torsion [36].

Some beneficial effects of pounding were reported during the 1971 San Fernando earthquake [37]. The direction of collapse of one of the staircases of the Olive View Hospital was altered away from the main building. In addition, contact of the main building with the adjacent structures supported the soft-storey that formed at the level of contact [23]. 


\section{SOIL-STRUCTURE INTERACTION}

The effects of soil-structure interaction on the dynamic response of a building are twofold. The first effect is on the free-field excitation and the second is on the response characteristics of the oscillating system.

\subsection{Effects of Soil-Structure Interaction on Seismic Excitation}

The presence of a soil layer above the bedrock will lead to a reduction in the bedrock motion due to overburden pressure. The ground motion at the free-field will either be amplified or attenuated depending on the following:

- Characteristics of the bedrock excitation (amplitude, frequency content and duration).

- Soil profile (lateral homogeneity, layering, presence of bedrock and thickness of layers)

- Topography of the site.

- Soil properties (shear strength modulus, Poisson's ratio, and mass density for each layer).

The amplification of the excitation at the free-field is limited by the shear strength of the soil as levels of excitation may be attained which will result in excessive soil deformations [38]. The strain-dependence of the soil properties renders the determination of the site response under seismic excitations a difficult exercise.

This aspect of soil-structure interaction (i.e. site soil effects on the seismic excitations affecting the structure) was implicitly considered in this study through the application of the free-field excitation directly at the base nodes of the soilstructure interaction models.

\subsection{Effects of Soil-Structure Interaction on Structural Response}

Due to the presence of the supporting soil medium, the dynamic characteristics of the structure are modified as follows:

- The introduction of additional vibration modes (rocking and an average horizontal translation) compared to a fixed-base assumption. These modes are induced by the deformations at foundation level due to the base shear and moment.

- The effects of these rigid-body components of motion are to vary the inertial forces along the height of the structure due to the change in the vibration mode shapes.
- In addition, the natural periods of the structure are lengthened with repercussions on element ductility demands and overall system response.

- Waves emanating from the foundation-soil interface dissipate energy, leading to an increase in damping. This damping is effected in two forms:

i. Through the energy transmitted by the waves.

ii. Through material (hysteretic) damping in the soil.

These waves may be reflected back into the bounded domain (which comprises the structure and adjacent soil medium within the artificial boundary) in the case of a layered soil medium.

The fundamental frequency of the soil layer determines the extent of radiation damping, which will occur. If the excitation frequency is less than the fundamental frequency of the soil layer (as in the case of a shallow layer underlain by bedrock), damping will not occur and only material damping is present. This property of the soil layer is known as the cut-off frequency [39].

\section{THROUGH-SOIL COUPLING}

When the proximity of structures is such that pounding is a realistic possibility, the transfer of dynamic response effects through the soil must also be taken into consideration. Although the investigation of the soil-structure interaction phenomenon has developed at a notable pace, the same cannot be said of the through-soil coupling problem. The development of comprehensive mathematical models, and the analytical or numerical solution thereof, are daunting tasks in light of the many parameters involved. Various analytical [41] and finite element [42] techniques have been utilised in the development of the dynamic stiffness matrix for multifoundation systems. Modern numerical solution methods, however, rely on a combined boundary element-finite element approach [43]. In addition, experimental validation of the analytical and numerical investigations has also been conducted by a number of researchers $[44,45]$.

The most significant effect of the presence of an adjacent foundation is the introduction of certain modes of response that are not apparent in the single foundation case. In addition, some of the degrees-of-freedom will be coupled. The extent of this interaction is dependent mainly on the mass ratio of the adjacent structures, their (compliant foundation) natural frequencies, and the predominant frequency of the excitation. 


\section{PHYSICAL REPRESENTATION OF SOIL- STRUCTURE INTERACTION}

The determination of the dynamic force-deformation characteristics of the soil medium necessitates the solution of a wave-propagation formulation for all modes of vibration. In order to derive a (frequency dependent) solution, many simplifying assumptions are necessary, such as:

- Foundation wall-soil surface contact condition.

- Foundation shape (geometry).

- Soil profile and properties.

- Foundation rigidity (which affects the stress distribution at the foundation-soil interface)

Simple physical models in the form of frequency independent mass-spring-dashpot systems have been developed based on the solution of the pertinent wave-propagation equations.
These discrete element models are representative of the properties of the unbounded soil and are amenable to application in design office software. Many researchers have, over the past 30 years or so, developed models of varying degrees of complexity for different foundation geometries, soil profiles, embedment conditions, and modes of vibration [40]. The coefficients of these elements were obtained through suitable curve-fitting techniques to obtain a best-fit with the rigorous analytical or semi-analytical solutions.

In the present study, a discrete element representation incorporating a system of frequency-independent springs and dashpots, based on the model proposed by Mulliken and Karabalis [46], has been utilised to represent the soil flexibility effects. The through-soil coupling coefficients of this system are based on rigorous boundary element solutions of a massive foundation on a linear elastic half-space while the soil-structure interaction components of this model are similar to those presented by Gazetas [40], Richart et al. [47], and Wolf [48]. This model, the coefficients of which are presented in Table 1 , is then incorporated directly into RUAUMOKO.

Table 1: Coefficients for one-dimensional discrete element model [46].

\begin{tabular}{|l|c|c|c|}
\hline \multicolumn{1}{|c}{ MOTION } & HORIZONTAL & VERTICAL & ROCKING \\
\hline $\begin{array}{l}\text { Mass (inertia) } \\
\text { ratio, } \beta\end{array}$ & $\frac{m(7-8 v)}{32 \rho r_{o}^{3}(1-v)}$ & $\frac{m(l-v)}{4 \rho r_{o}^{3}}$ & $\frac{3(1-v)}{8 \rho r_{o}^{5}}$ \\
\hline $\begin{array}{l}\text { Equivalent radius, } \\
r o\end{array}$ & $2 a / \sqrt{\pi}$ & $2 a / \sqrt{\pi}$ & $2 a / \sqrt[4]{3 \pi}$ \\
\hline $\begin{array}{l}\text { Virtual soil mass } \\
\text { (inertia), } m_{v}\end{array}$ & $0.095 m / \beta$ & $0.27 m / \beta$ & $0.24 m / \beta$ \\
\hline $\begin{array}{l}\text { Discrete element } \\
\text { model, } K \text { (static } \\
\text { stiffness) and } C \\
\text { (damping) }\end{array}$ & $\begin{array}{l}K=9.2 \mathrm{Ga} /(2-v) \\
C=0.163 \mathrm{Ka} / V_{s}\end{array}$ & $\begin{array}{l}K=4.7 \mathrm{Ga} /(1-\mathrm{v}) \\
C=0.8 \mathrm{Ka} / \mathrm{V}_{s}\end{array}$ & $\begin{array}{l}K=4.0 \mathrm{G} a^{3} /(1-\mathrm{v}) \\
C=0.6 \mathrm{Ka} / \mathrm{V}_{s}\end{array}$ \\
\hline
\end{tabular}




\section{PARAMETERS USED IN THIS STUDY}

\subsection{Moment-resisting frames}

The configuration incorporated in this study comprises adjacent two-bay twelve- and six-storey reinforced concrete momentresisting frames of equal storey heights $(3.65 \mathrm{~m})$ designed according to the principles of the capacity-design method [35]. The twelve-storey two-bay frame [56] is designed in accordance with the latest versions of the relevant New Zealand design codes $[25,26]$ while the six-storey two-bay frame [49] was designed in compliance with earlier versions of the same codes. The mass ratio of the two buildings is $1: 2.29$ while the ratio of fixed-base periods is $1: 2.32$. The more flexible 12 storey frame is located to the left of the six-storey frame.

For the numerical models implemented in RUAUMOKO [24], a bilinear moment-curvature (post-yield stiffness, $r=10 \%$ ) is assumed for all inelastic elements (beams and ground floor columns) of the twelve-storey building. In the six-storey frame, all inelastic beams and columns are modelled by the modified Takeda degrading stiffness hysteresis rule [50]. These differences in the design and numerical modelling of the two buildings reflect the difficulties inherent in the practical assessment of pounding as the buildings are often owned by different parties.

The Constant Damping model [24] (5\% damping for all modes) incorporated in this study obviated the need to specify different damping ratio for each of the sub-systems (i.e. the superstructures and the soil mass). Ideally, an appropriate hysteresis rule (such as the Ramberg-Osgood rule) or a suitable element (e.g. friction element [39]) may be used to represent the material damping of the soil if non-linear soil behaviour is expected.

Leger and Dussault [51] noted that for long-period structures (i.e. $\mathrm{T}>1.5$ seconds) the choice of a Rayleigh damping model (initial elastic stiffness or instantaneous tangential stiffness) does not affect the seismic response.

The assumptions applied in the development of a numerical model for the moment-resisting frames for implementation in RUAUMOKO are as follows:

- Effective areas $\left(A_{\text {eff. }}\right)$ for all elements are taken as $A_{\text {eff. }}=$ $0.5 A_{g}$ (where $A_{g}$ is the gross area of the prismatic elements) to account for cracking of concrete elements [35]. Similarly, the shear area $\left(A_{\text {veff. }}\right)$ is considered to be half of the gross shear area $\left(A_{v}\right)$, where $A_{v}=5 / 6 A_{g}$ [52].

- Effective moments of inertia are as recommended in NZS 3101: 1995 [26]. These values were amended to account for the actual axial force levels in the columns.
- Rigid end-blocks are assumed for the inelastic beams and columns as this was considered to represent more accurately the actual condition with respect to the stiffness of the beam-column assemblage. The lengths of these blocks were equal to one-half the depth of the adjoining element at that joint [35].

- A plastic-hinge zone equal to one-half the section depth is assumed for all inelastic structural elements [35].

- Most pounding studies assume in-plane rigidity of the floor diaphragms. This implies the simultaneous contact of the total floor masses of the adjacent buildings. In fact, only the local masses of the impacting nodes are involved at the first instant of contact. Travelling wave effects in the floor diaphragm, in addition to its relative flexibility, lead to the gradual contribution of the other nodal masses at the same level at subsequent time stations. This is accounted for in the models of the present study through the independence of the lateral degrees of freedom of the nodes of each frame (i.e. the horizontal degrees of freedom for each level are unslaved).

- A Newmark Constant Average Acceleration integration scheme $(\beta=0.25)$ is implemented in the dynamic timehistory analyses.

- A lumped-mass matrix is utilised in the idealisation of the mass distribution of the structures. The results obtained under this assumption are sufficiently accurate and do not differ significantly from those of a distributed mass representation [53].

- The time-step used in all analyses is 0.001 seconds, which is comparable to the recommendations of other studies [10, 54]. Such a small temporal increment is necessary to detect the short-duration impact events. Comparison of various response values (envelopes and time-histories) which were calculated assuming different time-steps $\left(5 \times 10^{-4}, 1 \times 10^{-3}\right.$ and $5 \times 10^{-3}$ seconds) has shown that, while a discrepancy in impact force characteristics may be detected, the effect of this discrepancy on the other response values (at both global and local levels) is negligible.

\subsection{Impact elements}

Impact members were placed at all levels. A Hertzian Contact rule [55] was utilised as this has been shown to suitably represent the non-linear characteristics of impacts [1]. Stiffness of the impact members was taken [54] as the axial stiffness of the lower level (exterior) beams of the twelve-storey frame, to which was added an arbitrary width of slab (as per NZS 3101:1995, Section 4.3.3.7).

Research has shown the insensitivity of storey shears, maximum beam ductilities, and displacement responses to 
impact member stiffness. As noted by Maison and Kasai [12], only the local accelerations are affected by this parameter. Therefore, impact element stiffness is important in the development of floor response spectra but this was not considered in this study.

\subsection{Soil properties}

The assumptions incorporated in the application of the soil flexibility model in this study are as follows:

- All foundations were designed as square rigid surface foundations since the required embedment depth was considered to be negligible in comparison with the layer thickness. The presence of rigid tie beams ensured their stability in the lateral direction and enforced rigid behaviour of the foundation system (i.e. foundation flexibility was not considered). Perfect bond is assumed to exist between the footings and the surface of the supporting soil.

- The supporting soil mass is assumed to be an unlayered homogeneous soil deposit (clay) the properties of which are indicated in Table 2.

- Only radiation damping in the discrete element model is considered due to the assumption of a Constant Damping model (5\% for all modes) for the numerical model incorporated in RUAUMOKO.
Table 2: Soil properties

\begin{tabular}{|cc|}
\hline Shear wave velocity, $V_{s}(\mathrm{~m} / \mathrm{s})$ & 102.06 \\
\hline Soil shear modulus, $G(\mathrm{MPa})$ & 18.75 \\
\hline Poisson's ratio, $v$ & 0.50 \\
\hline Mass density, $\rho\left(\mathrm{kg} / \mathrm{m}^{3}\right)$ & 1800 \\
\hline
\end{tabular}

- Material damping of the soil was not accounted for in the soil-structure interaction models and only radiation damping was represented. This was due to the application of a constant damping model in the numerical model of the total structure-soil system. This model was deemed to be representative of the total system damping. In addition, at the time this study was conducted RUAUMOKO did not allow for specification of separate values for the damping characteristics of the various components (momentresisting frames, impact elements and soil mass) which comprise the total system. Subsequent software upgrades, however, have overcome this limitation.

- Hysteretic soil damping has not been incorporated in this study as the soil is assumed to remain elastic.

Figure 2 is a schematic representation of the numerical model (moment-resisting frames and discrete elements) incorporated in RUAUMOKO.

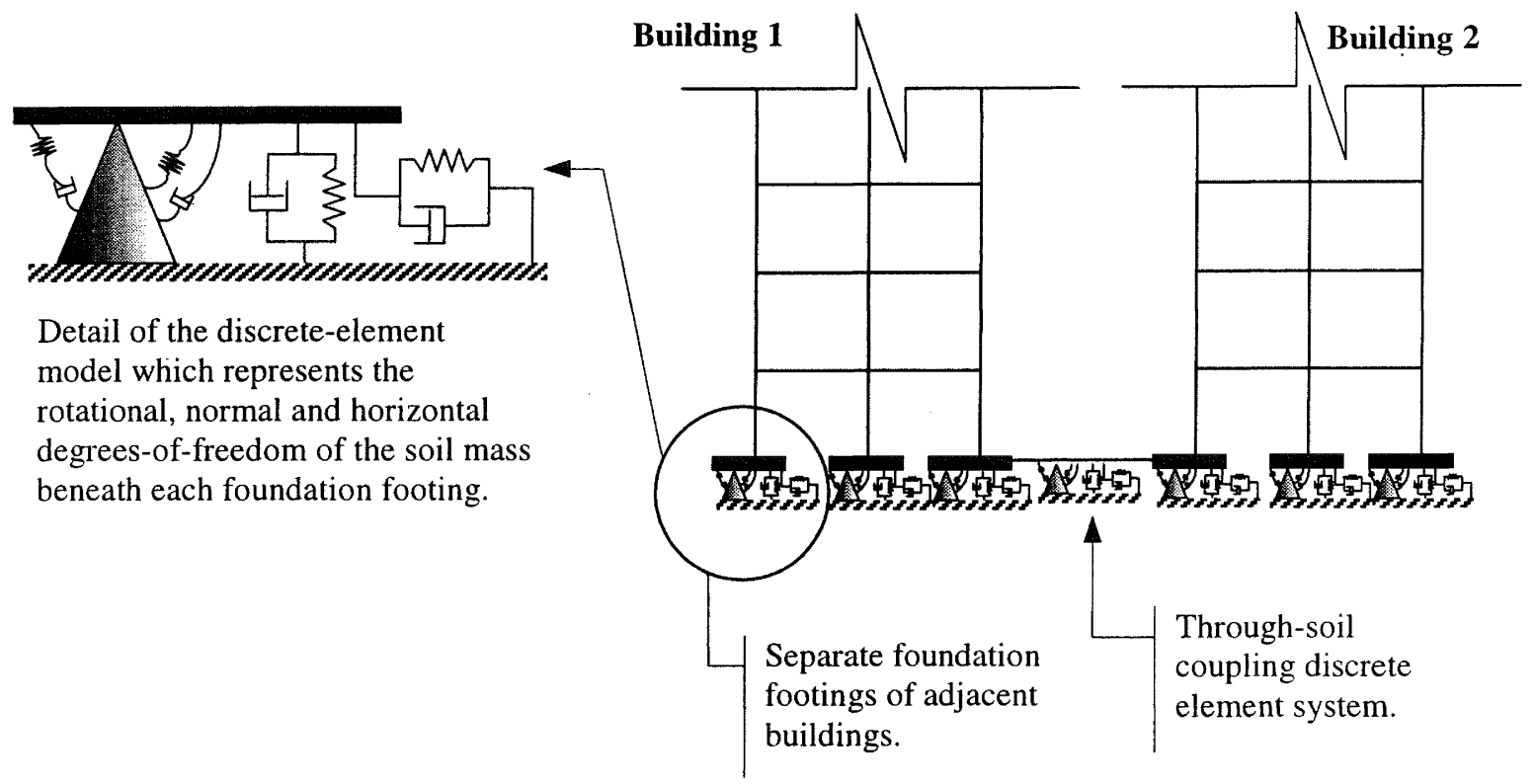

Figure 2: Numerical model representative of the moment-resisting frame and soil flexibility. 


\subsection{Earthquake Records}

The time-history analyses were of twenty-second duration consisting of a fifteen-second forced-vibration stage under an actual earthquake accelerogram and a free-vibration segment of five-second duration. Two different earthquake excitations were used: the 1940 El Centro earthquake (N-S component) (Figure 3(a)) and the Sylmar County Hospital accelerogram (Figure 4(a)) recorded during the 1994 Northridge earthquake. The El Centro earthquake record has a peak ground acceleration (PGA) of $0.35 \mathrm{~g}$ and is representative of a benchmark excitation, commonly used in structural dynamics studies and aseismic design codes (e.g. Ref. 25). The Sylmar County Hospital record has a PGA of $0.8 \mathrm{~g}$ and a single large amplitude acceleration pulse typical of a near-fault event.

The direction of seismic attack is an important aspect which is worthy of consideration in pounding studies [5, 54]. This is due to its influence on the time at which the first impact occurs, the dynamic response of the individual systems and the hysteretic behaviour assumed in the numerical models. Therefore, the pounding response resulting from the above earthquake records applied from opposite directions was also compared.
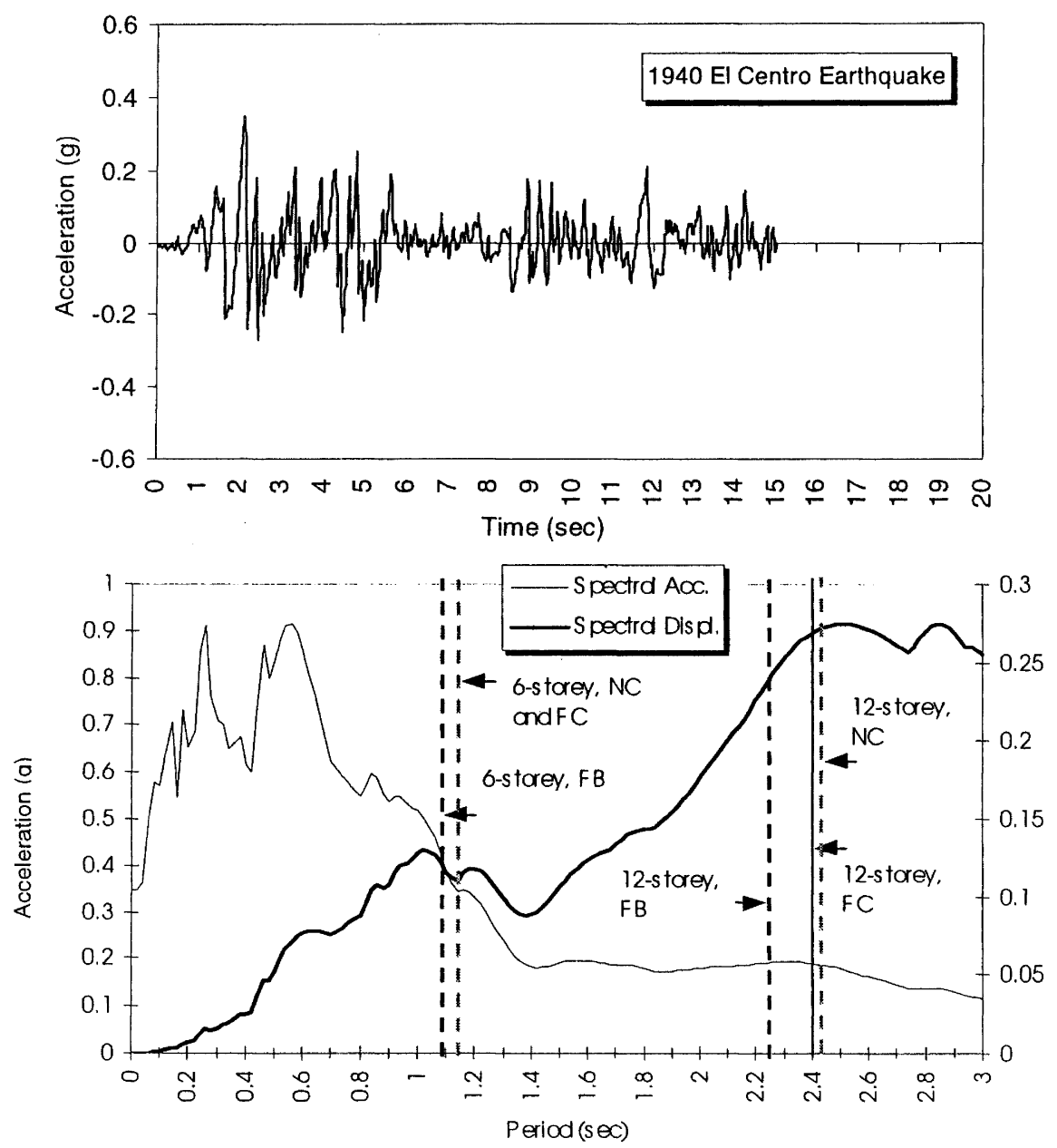

(a) Acceleration time-history

$$
\begin{array}{cl} 
& \mathrm{FB}=\text { Fixed } \text { Base } \\
& \mathrm{NC}=\text { Non-coupled foundations } \\
\widehat{\widehat{\underline{\mathrm{E}}}} & \mathrm{FC}=\begin{array}{c}
\text { Foundations coupled (i.e. } \text { with } \\
\text { through-soil interaction) }
\end{array}
\end{array}
$$

(b) Spectral response values

Figure 3: 1940 El Centro accelerogram and effect of soil flexibility on spectra response values. 


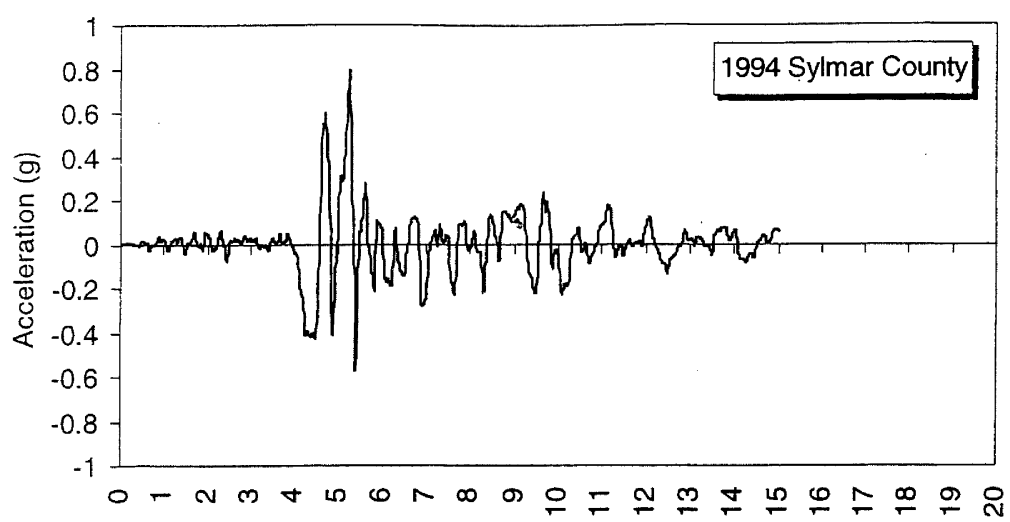

Time (sec)

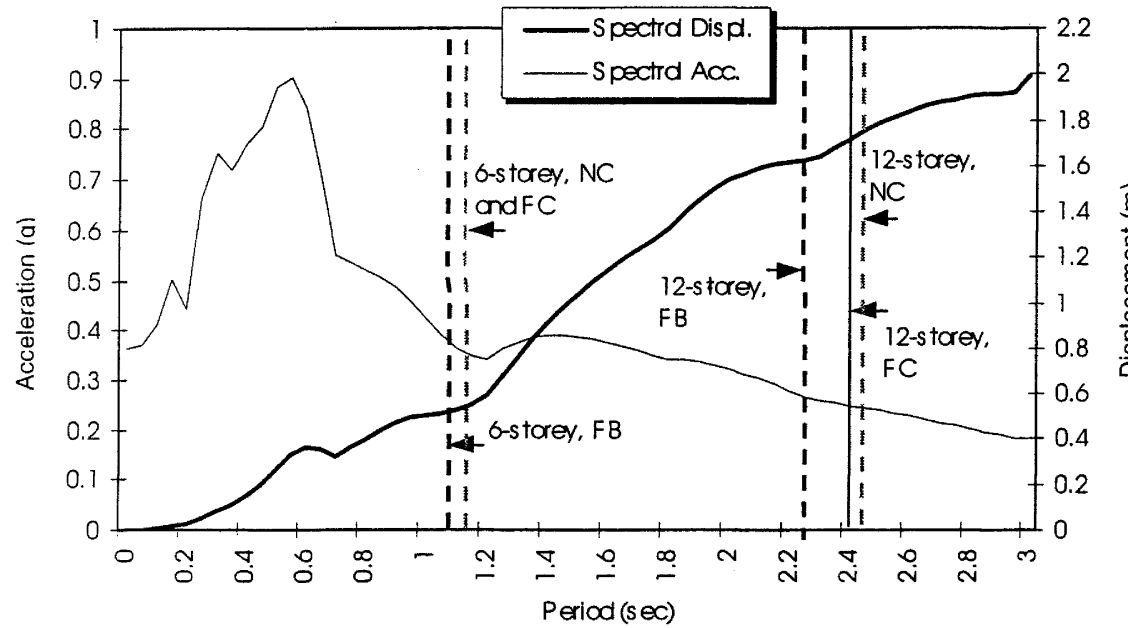

(a) Acceleration time-history

$\mathrm{FB}=$ Fixed Base

$\mathrm{NC}=$ Non-coupled foundations

$\mathrm{FC}=$ Foundations coupled (i.e. with through-soil interaction)

(b) Spectral response values

Figure 4: 1994 Sylmar County Hospital accelerogram and effect of soil flexibility on spectral response values.

\subsection{Separation Gaps}

Various separation gaps, based on different levels of codespecified static loadings, are considered. The New Zealand Loadings Code (Section 2.5.4.2) [25] stipulates the separation of adjacent structures a distance equal to the sum of the their maximum design lateral displacements for the ultimate limit state. In this study, three initial separation gaps are implemented:
- A $1 \mathrm{~mm}$ gap, simulating complete contact, i.e. no separation gap case.

- An arbitrary intermediate value of $10 \mathrm{~mm}$.

- $\quad 24 \mathrm{~mm}$, which is the minimum requirement of NZS 4203: 1992 
The no-pounding case, in which a distance sufficient to preclude pounding ( 2 metres) separated the adjacent buildings, was used as a benchmark. A separation gap of $75 \mathrm{~mm}$, equal to the elastic displacement of the twelve-storey frame (determined from an equivalent lateral static force analysis), was also considered. However, it was not further investigated due to the limited number of impacts and their restriction to the upper levels.

\section{RESULTS AND OBSERVATIONS}

In this paper, assessment of pounding effects is through comparison of the variations due to foundation fixity conditions of the maximum impact forces for the various initial separation gaps.

The influence of soil-structure interaction on the dynamic response characteristics of the individual frames (i.e. nopounding) case is presented first.

\subsection{No-pounding case}

The main effect of soil-structure interaction is the increase of the natural periods of the oscillating systems. For the twelvestorey and six-storey frames, the increase from the fixed-base case is $7 \%$ ( 2.27 seconds to 2.43 seconds) and $4.6 \%$ (from 1.09 seconds to 1.14 seconds), respectively. The effects of this shift in the natural periods of the two buildings with respect to the response spectra of the two excitations implemented in this study are shown in Figures 3(b) and 4(b) and outlined in Table 3. An increase in maximum top storey displacements in both buildings, biased towards the direction of earthquake attack, may be observed in Figure 5. In addition, foundation compliance results in a phase shift in the displacement timehistory as is shown in Figure 6 for level 12 of the twelve-storey building. This phase shift is especially evident in the freevibration phase of the response, where the fixed base and compliant foundation time-histories are out-of-phase.

The effects of through-soil coupling on the displacement response of the structures were not particularly evident for the soil conditions (clay) and no-pounding separation gap (2 metres) assumed in this study.

The variations in the maximum values of the impact-side column shears for both cases of earthquake loading and for both frames (Figure 7) did not exceed 5\% and are therefore negligible.
Table 3: Effect of foundation fixity on natural period of 12and 6-storey moment-resisting frames.

\begin{tabular}{|c|c|c|}
\cline { 2 - 3 } \multicolumn{1}{c|}{} & \multicolumn{2}{c|}{ Natural Period (seconds) } \\
\hline $\begin{array}{c}\text { Foundation } \\
\text { Fixity }\end{array}$ & $\begin{array}{c}\text { 12-storey } \\
\text { frame }\end{array}$ & $\begin{array}{c}\text { 6-storey } \\
\text { frame }\end{array}$ \\
\hline Fixed Base & 2.272 & 1.086 \\
\hline $\begin{array}{c}\text { Compliant (i.e. } \\
\text { non-coupled } \\
\text { foundations) }\end{array}$ & 2.427 & 1.139 \\
\hline $\begin{array}{c}\text { Foundations } \\
\text { Coupled }\end{array}$ & 2.406 & 1.136 \\
\hline
\end{tabular}

\subsection{Pounding case}

For the case of the $1940 \mathrm{El}$ Centro excitation, the following effects of soil flexibility may be noted:

- An increase in maximum impact forces at all levels and for both directions of excitation due to soil flexibility (Figure $8)$.

- Level 6 impacts are significantly higher than those developed at the other levels for both directions of seismic excitation.

- For the smaller separation gaps (1 $\mathrm{mm}$ and $10 \mathrm{~mm})$, the increases due to through-soil interaction in top level maximum impact forces are higher when the excitation is applied from the direction of the six-storey frame (20-30\% compared to $10-15 \%$ for the opposite direction of seismic attack). For the $24 \mathrm{~mm}$ separation gap, through-soil interaction resulted in a $35 \%$ increase in level 6 maximum impact force when the excitation was applied from the direction of the twelve-storey frame compared to an almost $20 \%$ increase for the opposite direction of seismic attack.

- For the case of excitation from the direction of the sixstorey frame, the influence of the initial separation gap on the magnitude of the top level maximum impact force is less than for the opposite direction of excitation. 


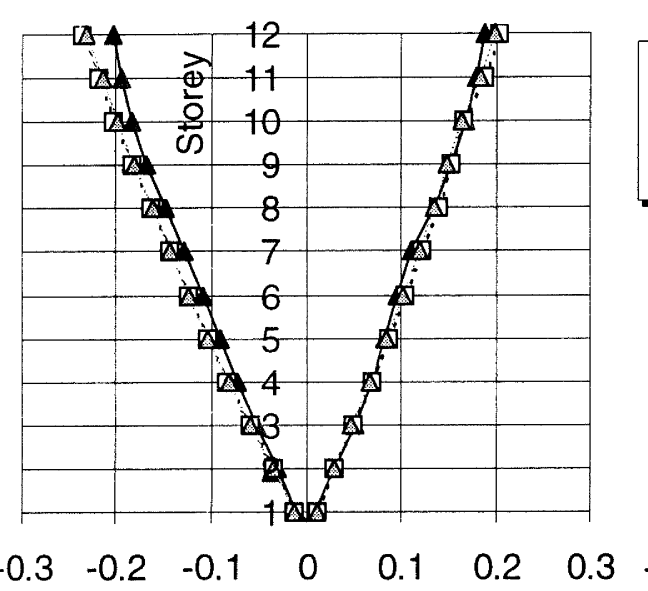

Relative Displacement (m)
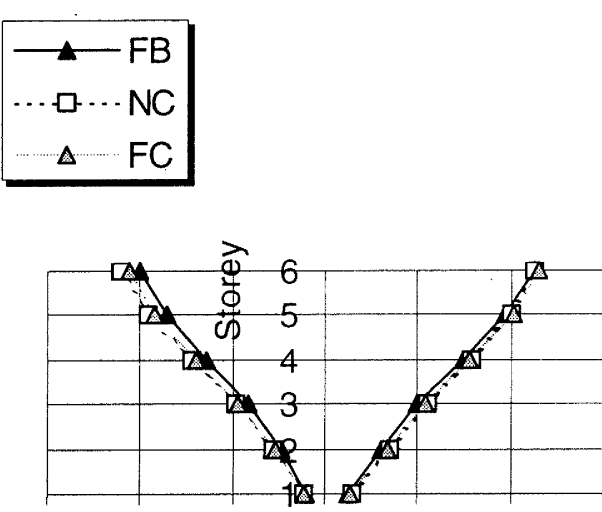

$\begin{array}{lllllll}-0.15 & -0.1 & -0.05 & 0 & 0.05 & 0.1 & 0.15\end{array}$

Relative Displacement (m)

Figure 5: Influence of soil flexibility conditions on lateral displacements for no pounding case. (Note: FB = Fixed Base, $N C=$ Non-coupled (i.e. without through-soil interaction), FC $=$ Foundations Coupled).

- Consideration of only soil-structure interaction (without through-soil interaction) resulted in conservative values of top level maximum impact forces (compared to a fixedbase assumption) in all cases of initial separation gap and direction of excitation. When through-soil interaction is included in the soil flexibility model it is evident that these increases are not as large as those implied when throughsoil interaction is neglected. The only exception is for the case of the $1 \mathrm{~mm}$ separation gap when the excitation is applied from the direction of the six-storey frame. An almost $30 \%$ increase of top level maximum impact force from the fixed-base case is evident when through-soil interaction is considered compared to the $20 \%$ increase for the model with soil-structure interaction only.

- The influence of excitation direction and foundation fixity conditions on the time-history of level 6 impact force is presented in Figure 9 ( $1 \mathrm{~mm}$ separation gap). Consideration of soil-structure interaction results in an increase in the number and magnitude of impact forces. The direction of the seismic excitation clearly influences the times at which the impacts occur in addition to the frequency content and magnitudes of impacts. The influence of through-soil coupling is not only on the magnitudes of the maximum impact forces but also on the lower magnitude impacts as well.
The following trends may be identified for the Sylmar County Hospital record (Figure 10):

- Level 6 impacts were much less sensitive to the foundation fixity condition than the El Centro excitation cases.

- For each case of seismic attack direction, the magnitudes of the maximum impact forces at all levels were less sensitive to the magnitudes of initial separation gaps for all cases of foundation fixity.

- The effects of foundation fixity assumption were highly apparent at the lower levels (2-4) for the case of seismic attack from the direction of the six-storey building.

- Incorporation of through-soil interaction in the soilstructure interaction model did not affect the maximum impact force magnitudes.

- The influence of excitation direction on the magnitudes and time-stations at which impacts occur is shown in Figure 11. For a particular direction of seismic attack, soil flexibility does not influence the magnitudes or the sequence of the impact forces. 

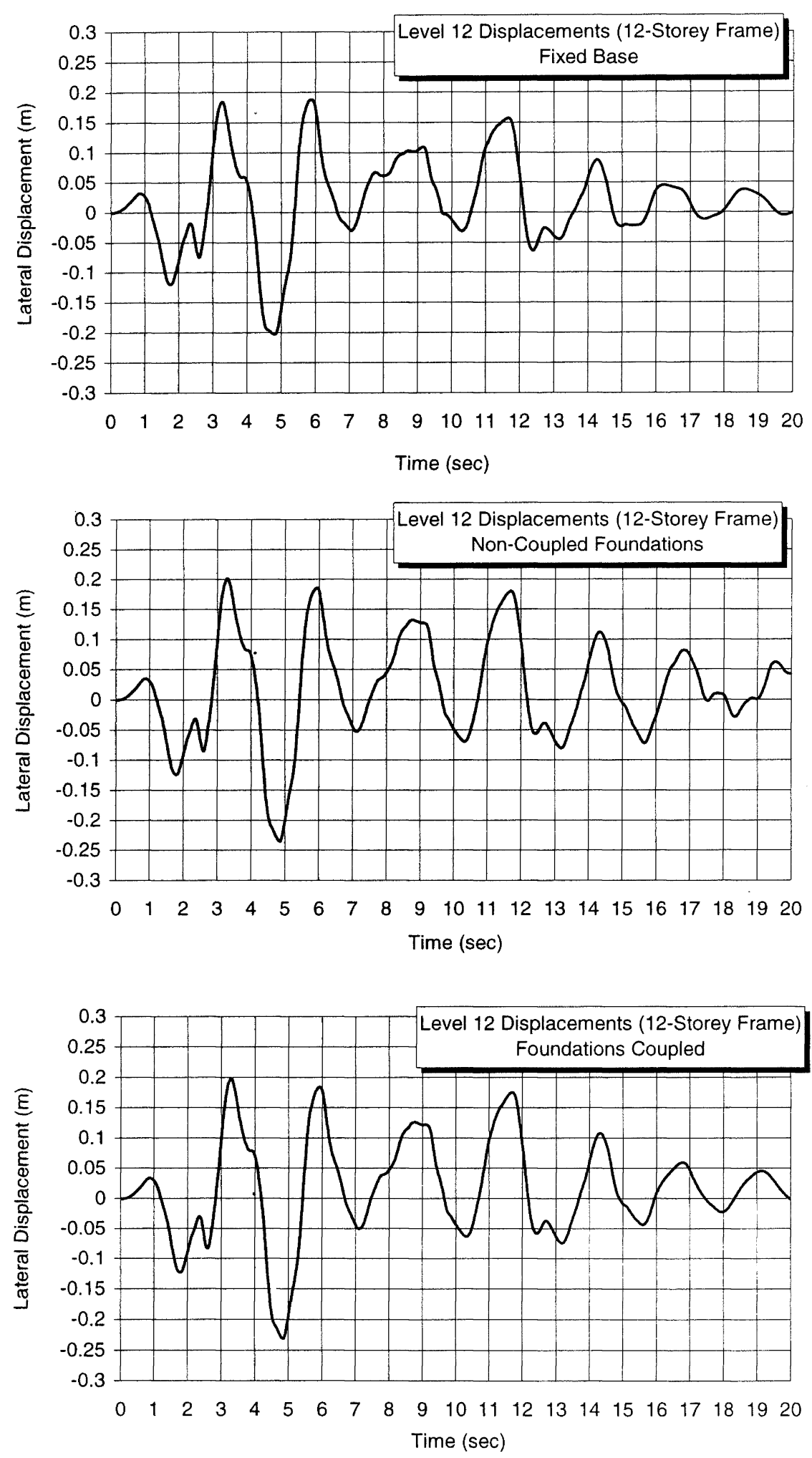

Figure 6: Influence of soil flexibility conditions on lateral displacement time-histories for no pounding case. 

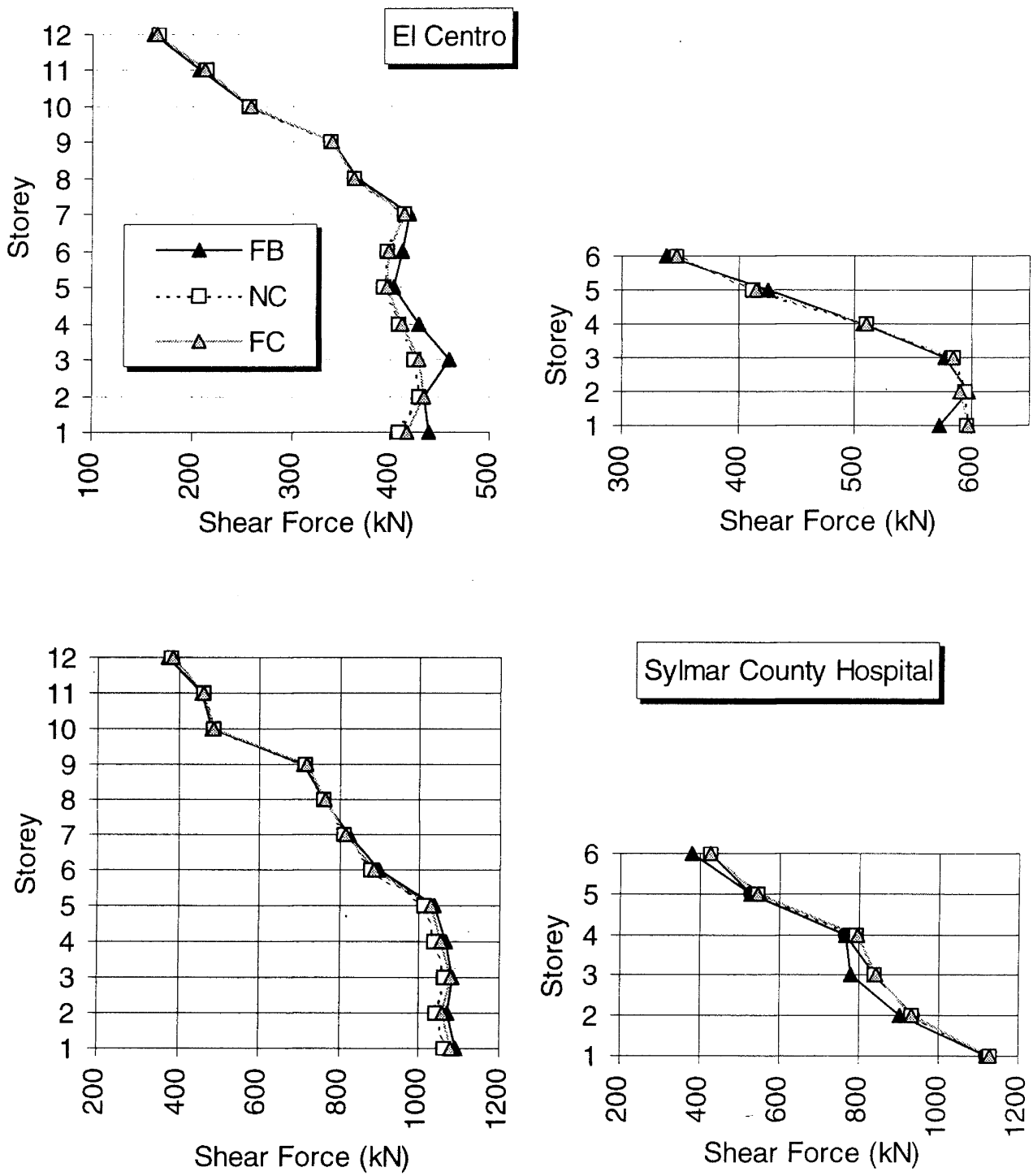

Figure 7: Influence of flexibility conditions on impact-side column shears for no pounding case. (Note: FB = Fixed Base, NC $=$ Non-coupled (i.e. without through-soil interaction), FC = Foundations Coupled).

\section{CONCLUSIONS}

The effects of foundation compliance are quite obvious even for the conventional structures studied herein. While the results cannot be extrapolated to other cases of structural configurations, the importance of soil flexibility has been highlighted in this study. The influence of factors such as the magnitude of initial separation gap and direction of seismic attack cannot be extrapolated from the fixed-base case. Simple soil flexibility models exist which can be easily incorporated into commercial structural analysis software.
The sensitivity of the pounding response to the characteristics of the applied earthquake is increased with the consideration of soil flexibility. This is mainly due to the increases in the natural periods of the adjacent buildings. Compliance effects must also be taken into account when determining the locations of sensitive equipment and appurtenances due to the localised effects of the large amplitude impacts.

Future studies will cover the effects of soil flexibility on other pounding response parameters such as the impact-side column shears and total floor accelerations. In addition, other cases of structural configurations will be investigated such as structures of similar total heights. 


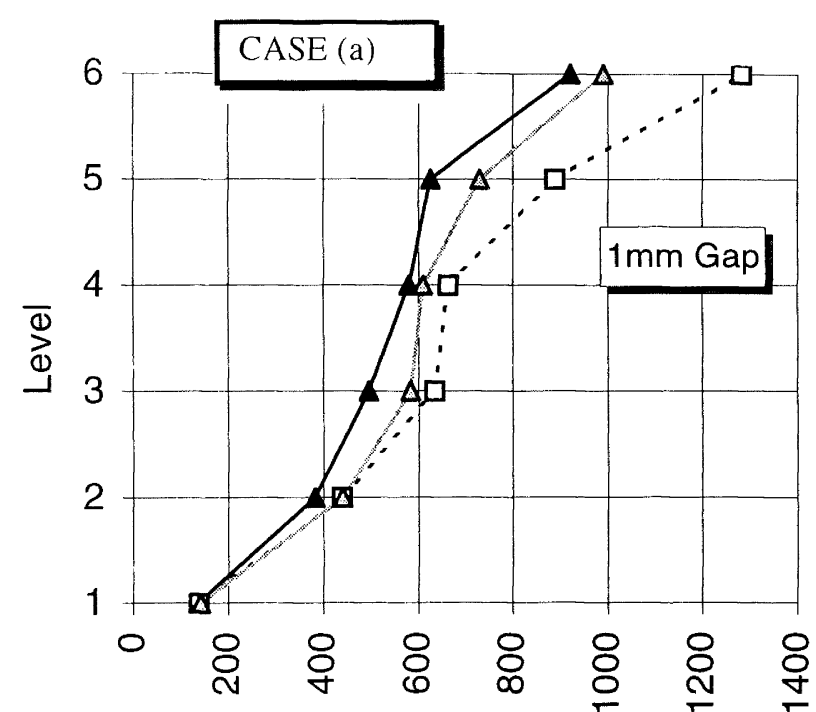

Impact Force (kN)

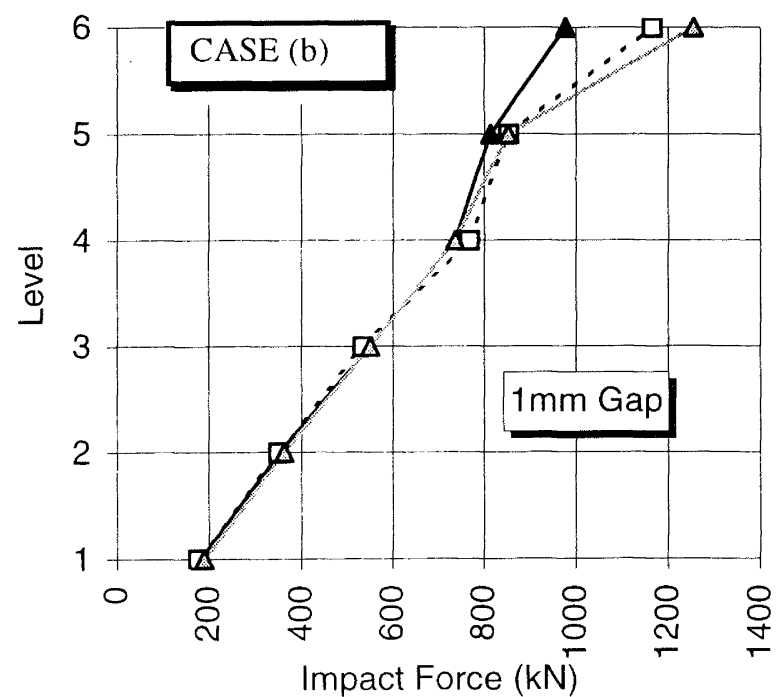

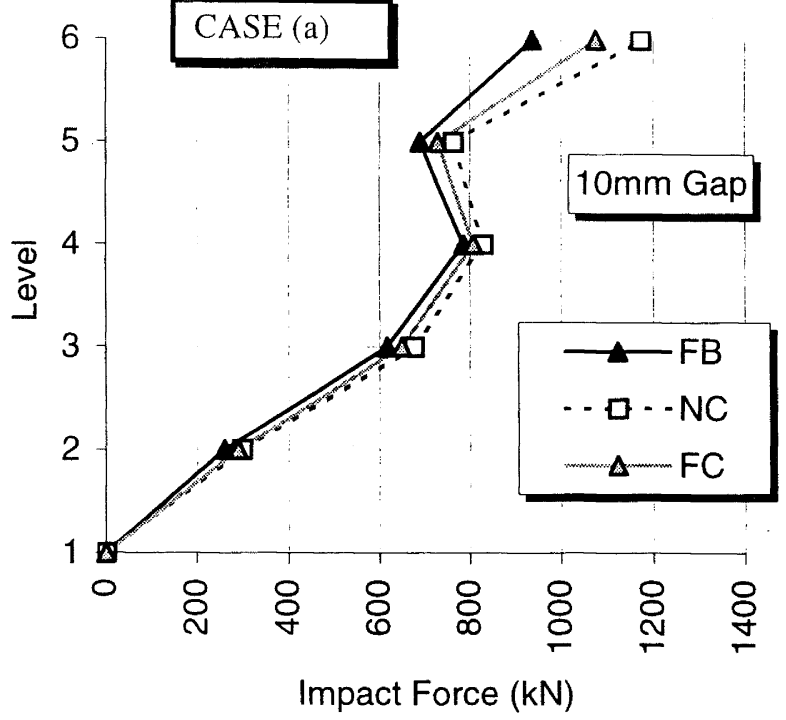
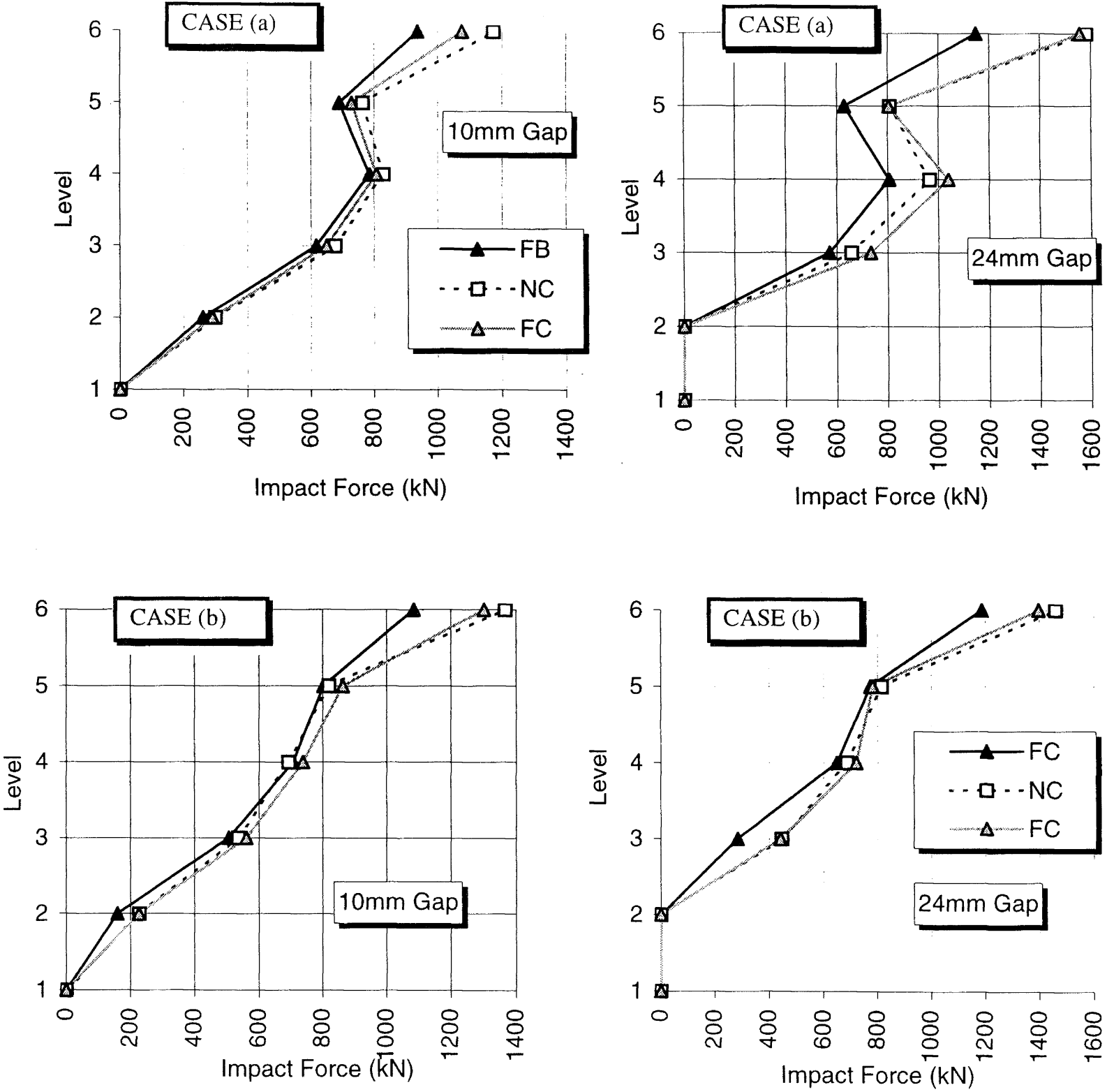

Figure 8: Influence of soil flexibility conditions on maximum impact forces for various separation gaps and directions of attack of El Centro earthquake (Case (a) = leftright, Case $(b)=$ right-left). (Note: FB = Fixed Base, NC= Non-coupled (i.e. without through-soil interaction), FC=Foundations Coupled). 


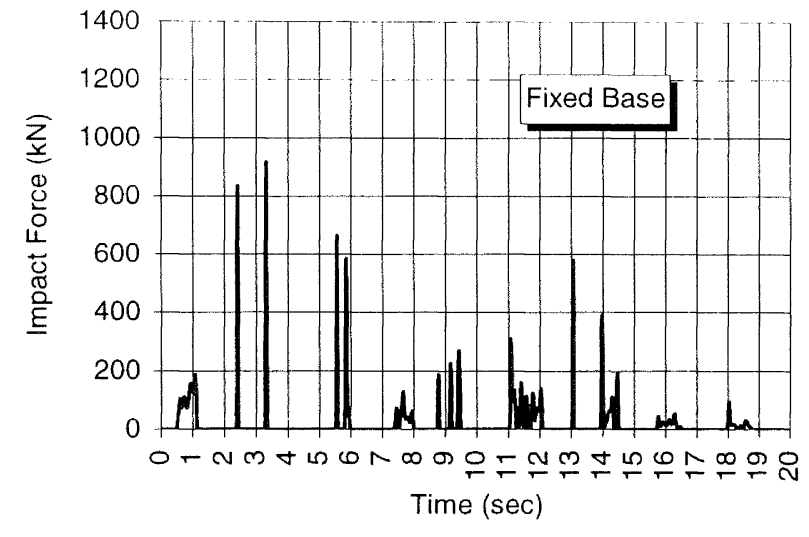

CASE (a): 1940 El Centro earthquake applied left-right

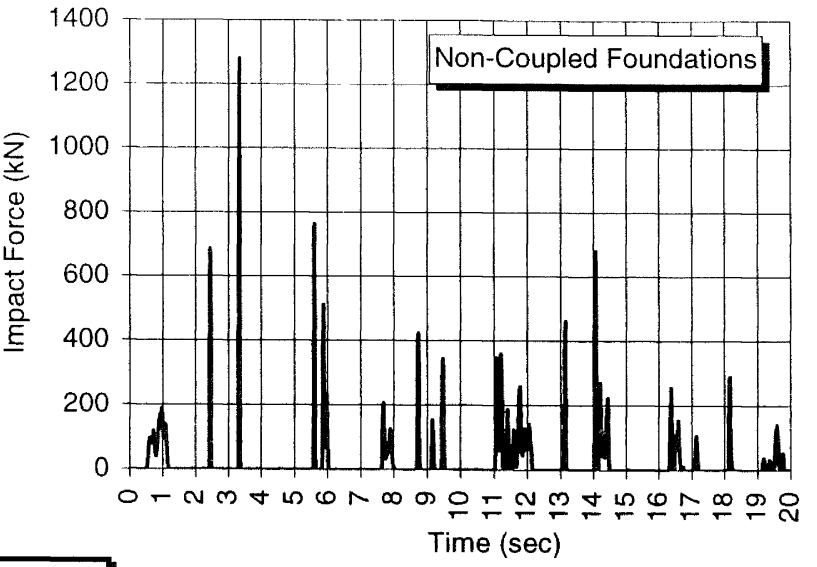

Time (sec)

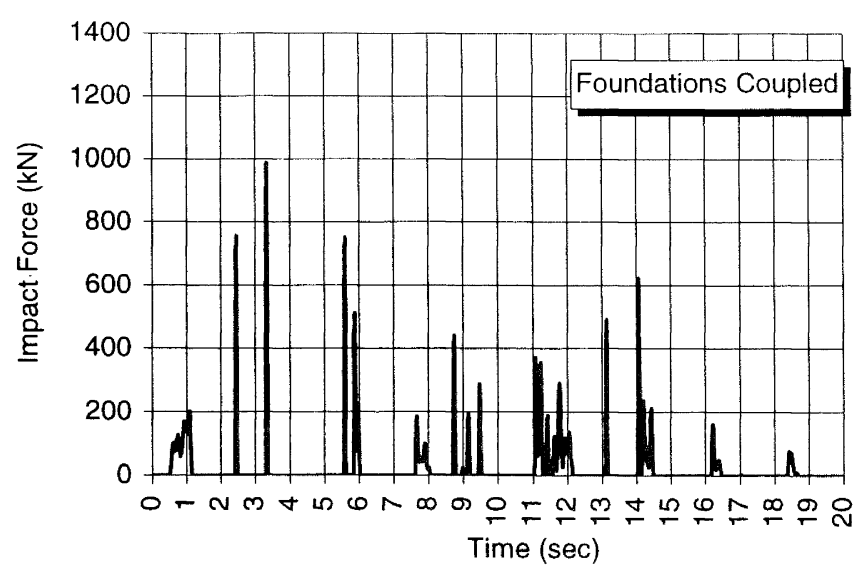

CASE (b): 1940 El Centro earthquake applied right-left

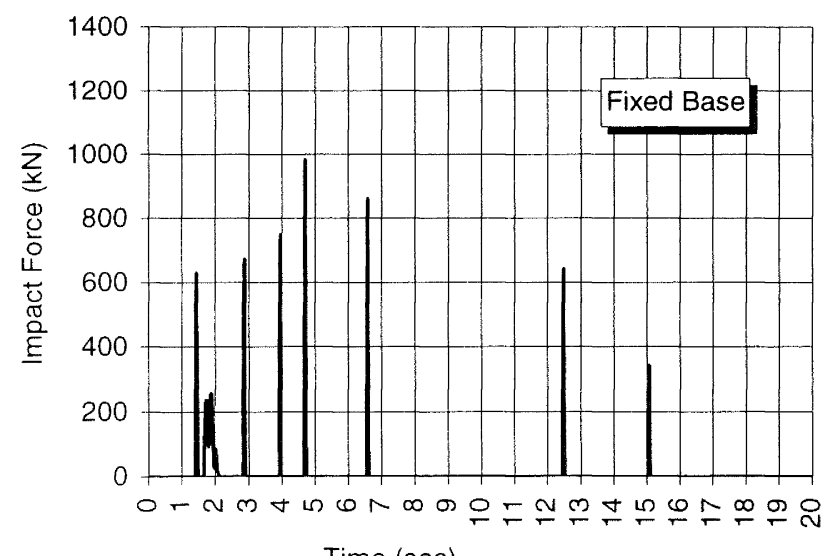

Time (sec)

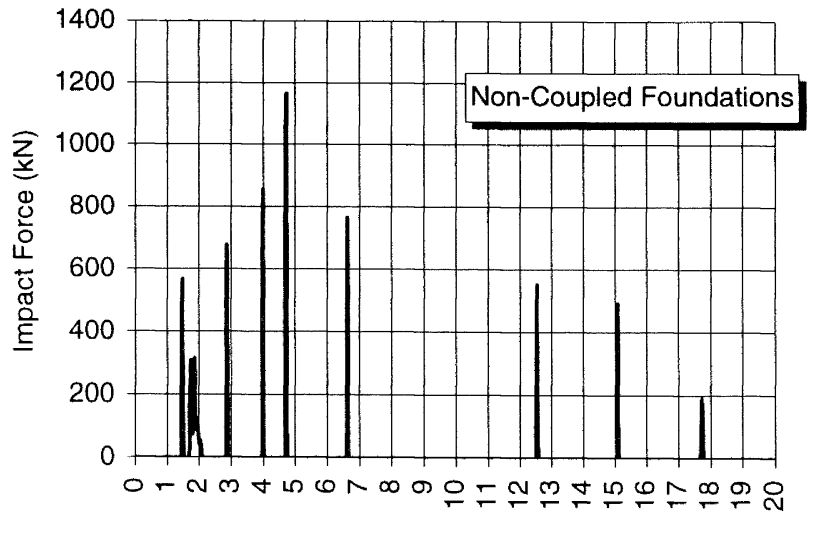

Time (sec)

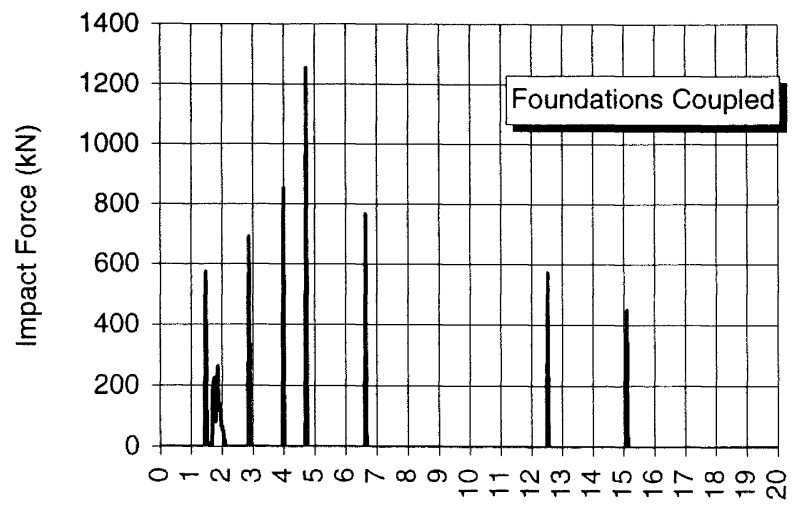

Time $(\mathrm{sec})$

Figure 9: Influence of soil flexibility conditions on impact force time-histories for 1 mm separation gap and separate directions of earthquake attack. (Note: FB = Fixed Base, $N C=$ Non-coupled (i.e. without through-soil interaction), FC = Foundations Coupled). 


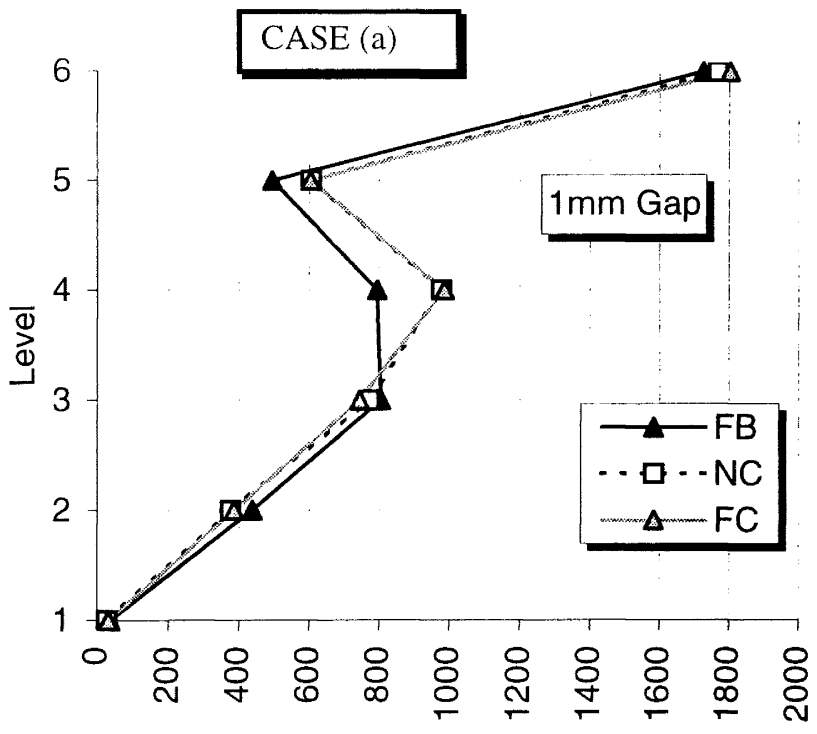

Impact Force $(\mathrm{kN})$

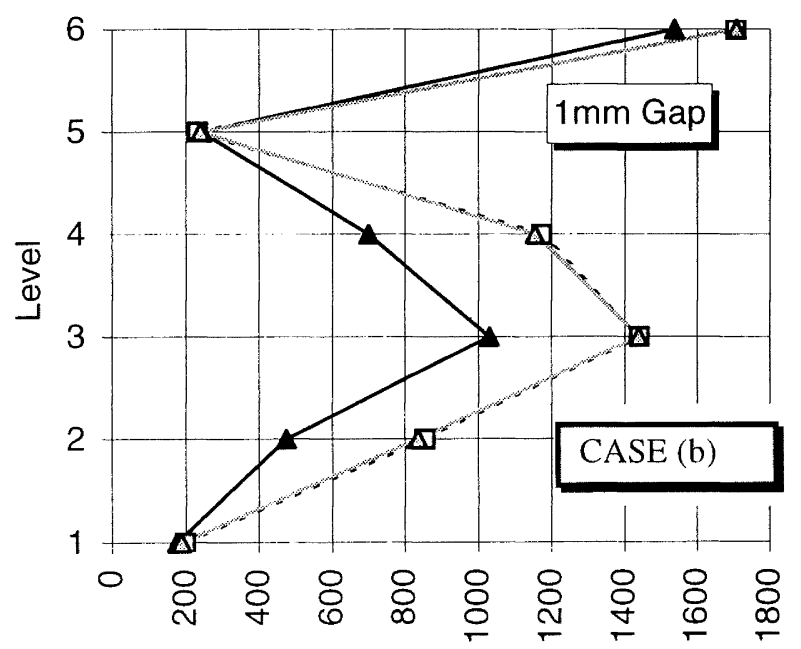

Impact Force $(\mathrm{kN})$
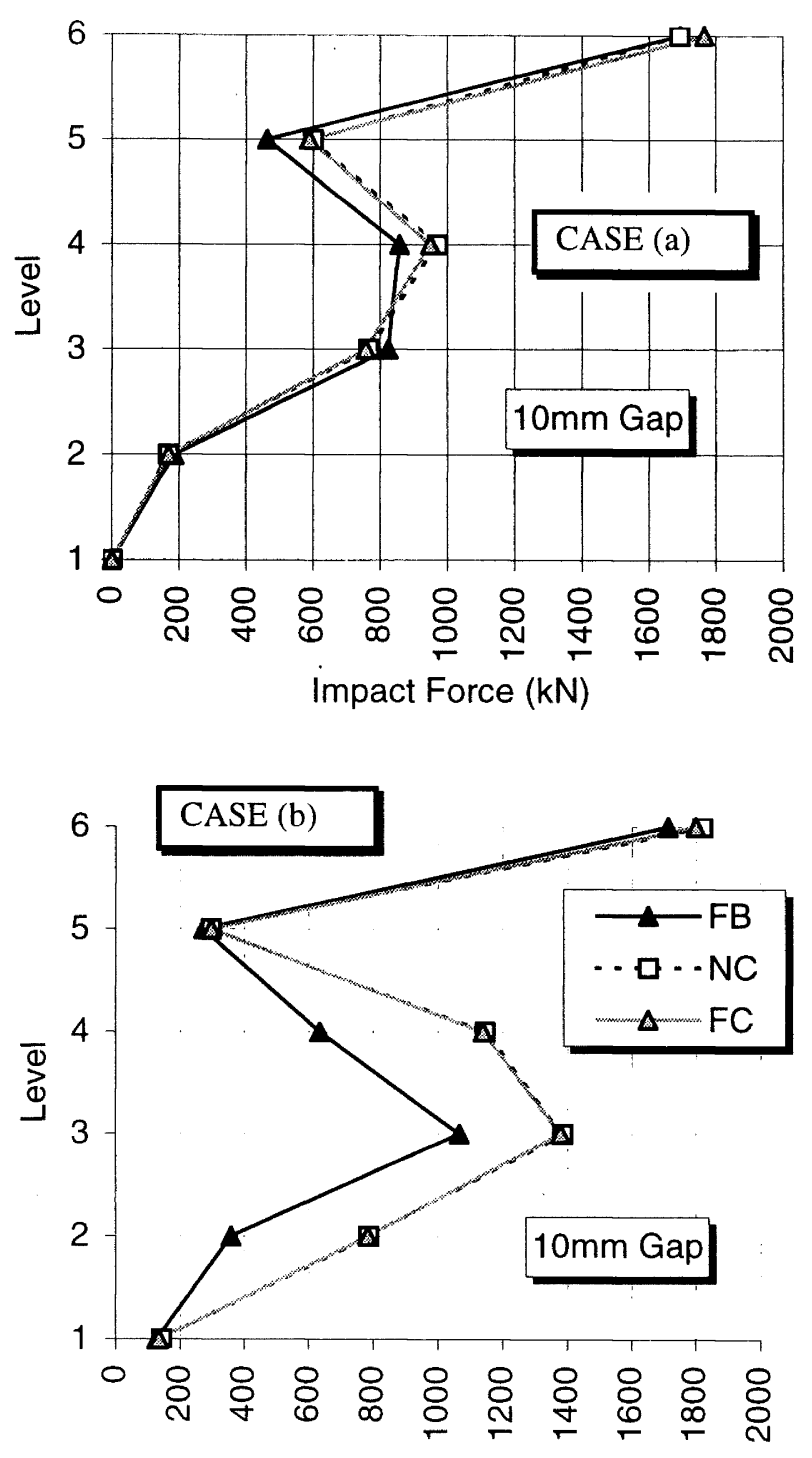

Impact Force $(\mathrm{kN})$
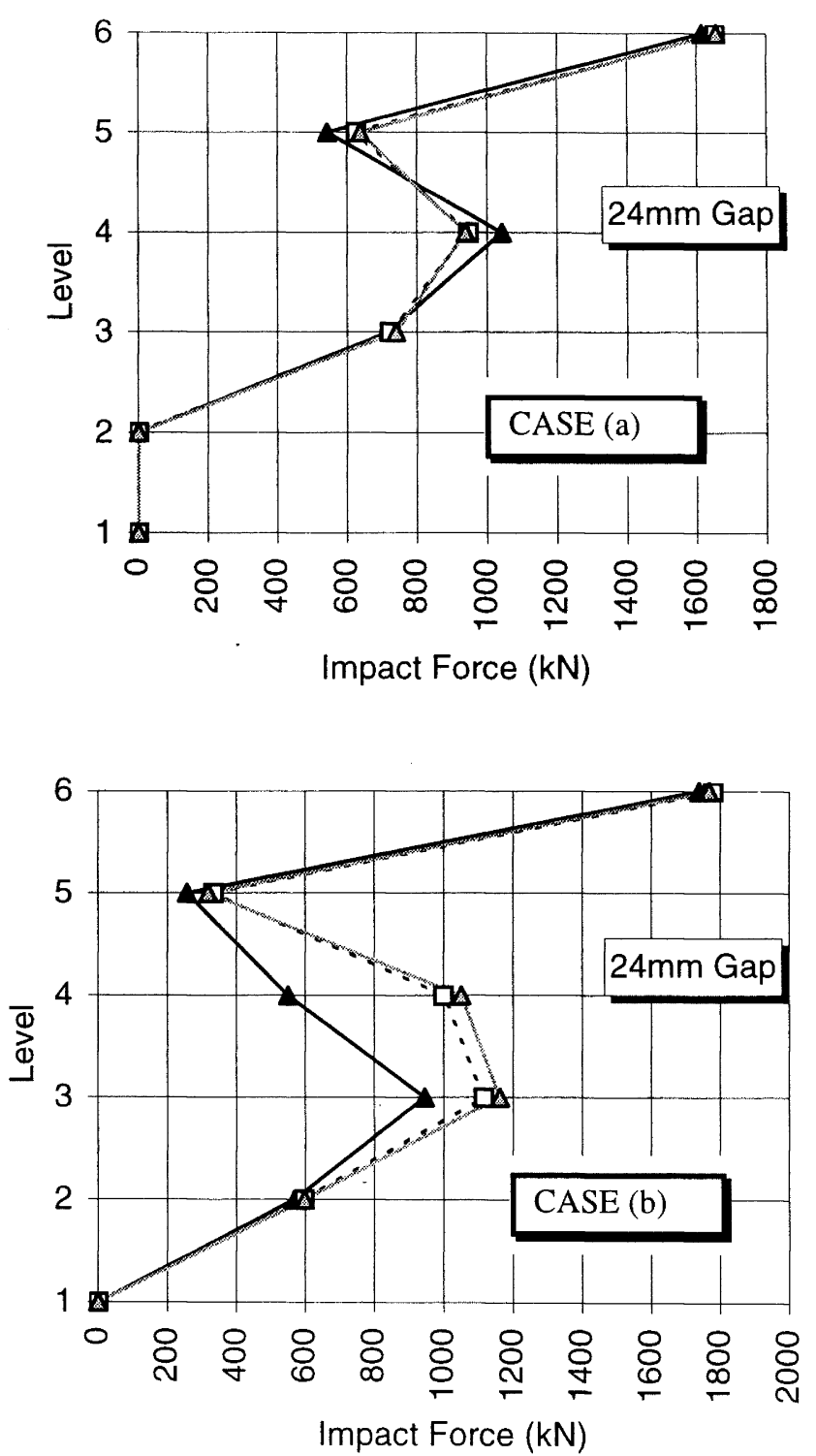

Figure 10: Influence of soil flexibility conditions on maximum impact forces for various separation gaps and directions of attack of Sylmar County Hospital earthquake record (Case $(a)=$ left-right, Case $(b)=$ right-left). (Note: FB $=$ Fixed Base, NC = Non-coupled (i.e. without through-soil interaction), FC = Foundations Coupled). 


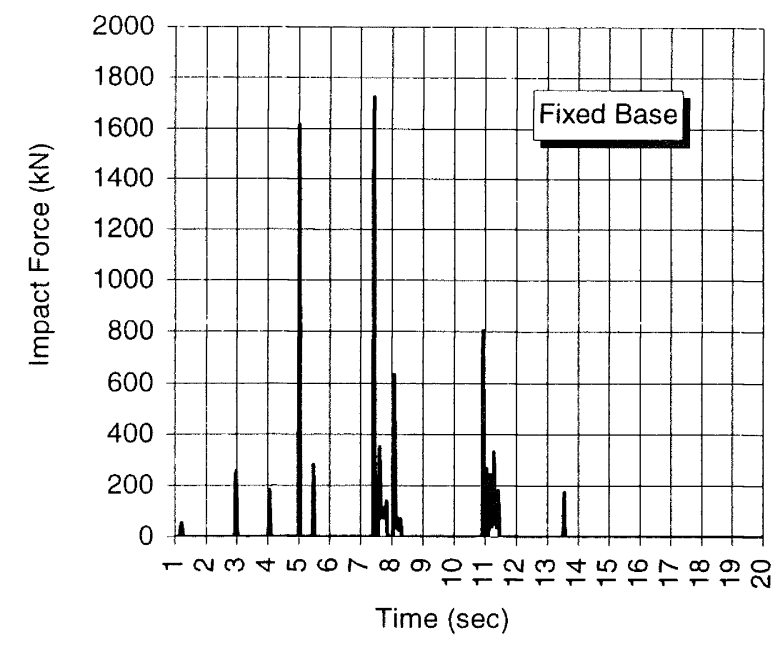

CASE (a): 1994 Sylmar County applied left-right

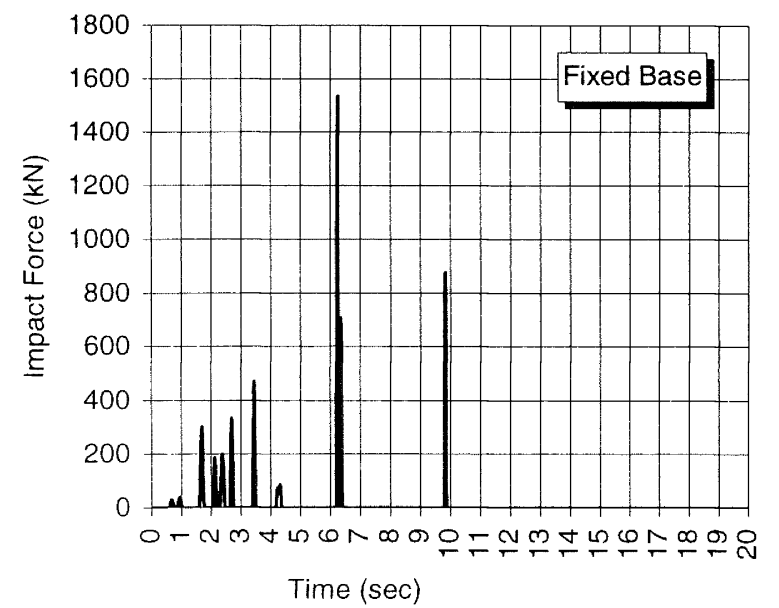

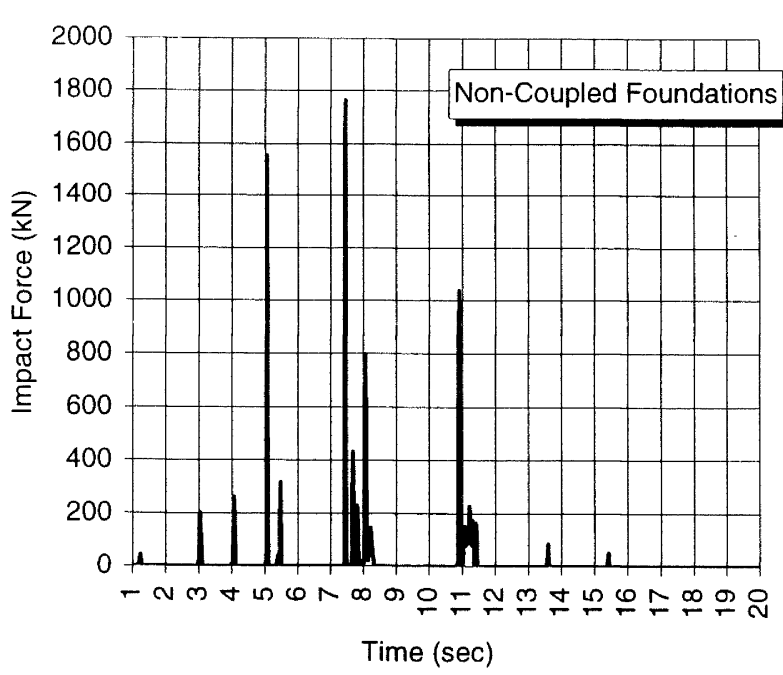

Time (sec)

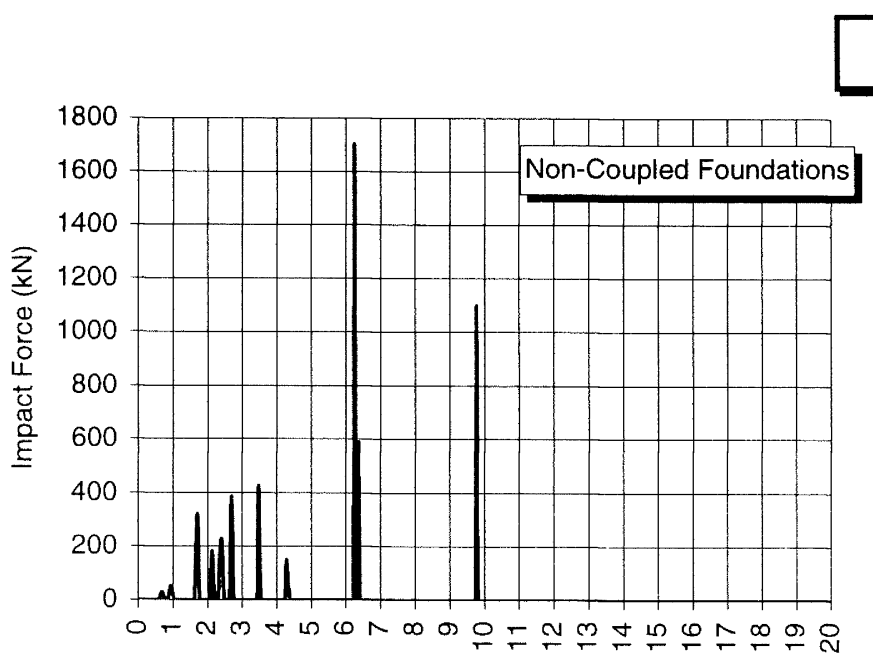

Time (sec)

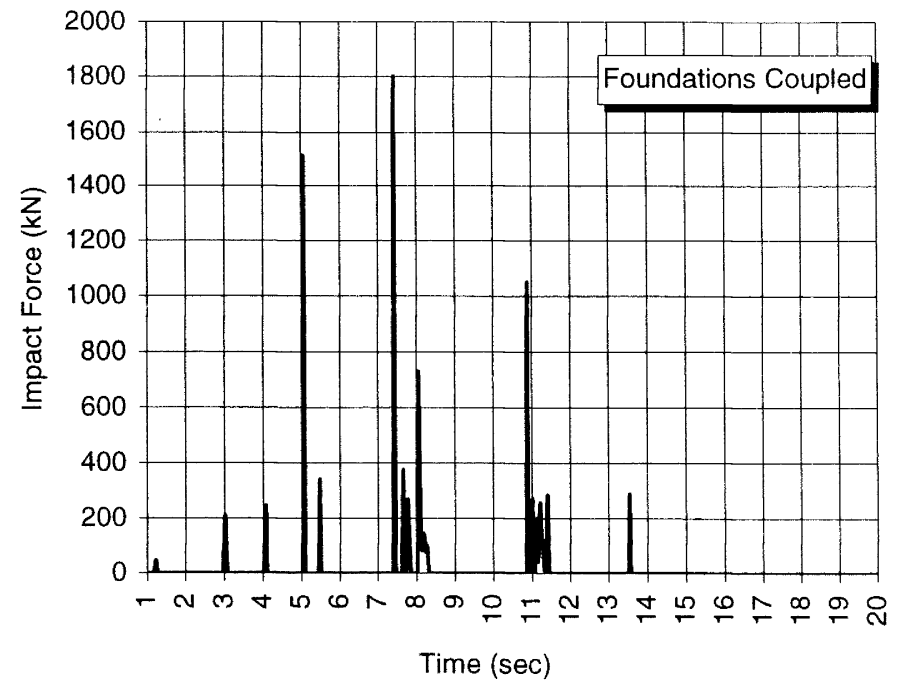

CASE (b): 1994 Sylmar County applied right-left

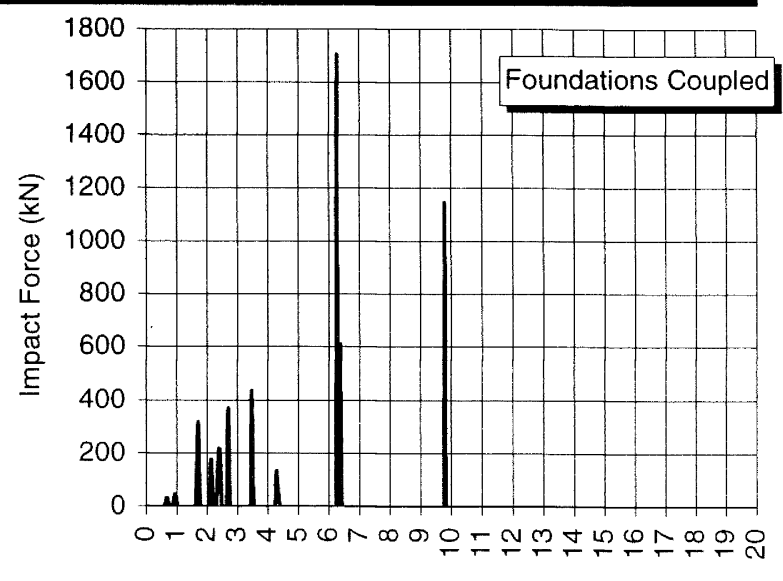

Time (sec)

Figure 11: Influence of soil flexibility conditions on impact force time-histories for 1 mm separation gap and separate directions of earthquake attack. (Note: FB = Fixed Base, NC = Non-coupled (i.e. without through-soil interaction), FC = Foundations Coupled). 


\section{REFERENCES}

1. Davis, R.O. (1992), "Pounding of buildings modelled by an impact oscillator", Earthquake Engineering and Structural Dynamics, 21: 253-274.

2. Jing, H.-S. and Young, M. (1990), "Random response of a single-degree-of-freedom vibro-impact system with clearance", Earthquake Engineering and Structural Dynamics., 19: 789-798.

3. Liolios, A.A. (1989), "A numerical estimation for the influence of modifications to seismic interaction between adjacent structures", Procedings International Conference on.Earthquake Resistant Construction and Design, (Ed.) R. Savidis, Balkema, Rotterdam: 461-467.

4. Jeng, V. and Kasai, K. (1996), "Spectral relative motion of two structures due to seismic travel waves", Journal of Structural Engineering, 122(10): 1128-1135.

5. Kasai, K., Jagiasi, A.R. and Jeng, V. (1996), "Inelastic vibration phase theory for seismic pounding mitigation", Journal of Structural Engineering, 122(10): 1136-1146.

6. Lin, J-H. (1997), "Separation distance to avoid seismic pounding of adjacent buildings", Earthquake Engineering and Structural Dynamics, 26: 395-403.

7. Penzien, J. (1997), "Evaluation of building separation distance required to prevent pounding during strong earthquakes", Earthquake Engineering and Structural Dynamics, 26, 849-858.

8. Valles, R.E. and Reinhorn, A.M. (1997), "Evaluation, prevention and mitigation of pounding effects in building structures", NCEER-97-0001, National Center for Earthquake Engineering Research Technical Report.

9. Hong, H. and Liu, X. (1998), "Estimation of required separations between adjacent structures under spatial ground motions", Journal of Earthquake Engineering 8(2): 197-215.

10. Anagnostopoulos, S.A. and Spiliopoulos, K.V. (1992), "An investigation of earthquake induced pounding between adjacent buildings", Earthquake Engineering and Structural Dynamics, 21: 289-302.

11. Filiatrault, A., Cervantes, M., Folz, B. and Prion, H. (1994), "Pounding of buildings during earthquakes: a Canadian perspective", Canadian Journal of Civil Engineering, 21: 251-265.

12. Maison, B.F. and. Kasai, K. (1990), "Analysis for type of structural pounding", Journal of Structural Engineering, ASCE, 116(4): 957-977.
13. Filiatrault, A. and Folz, B. (1992), "Nonlinear earthquake response of structurally interconnected buildings", Canadian Journal of Civil Engineering, 19: 560-572.

14. Westermo, B.D. (1989), "The dynamics of interstructural connection to prevent pounding", Earthquake Engineering and Structural Dynamics, 18: 687-699.

15. Wolf, J.P. and Skrikerud, P.E. (1980), "Mutual pounding of adjacent structures during earthquakes", Nuclear Engineering Design, 57: 253-275.

16. Xu, Y.L., He, Q. and Ko, J.M. (1999), "Dynamic response of damper-connected adjacent buildings under earthquake excitation", Engineering Structures, 21: 135-148.

17. Bertero, V.V. (1987), "Observations on structural pounding", The Mexico Earthquakes- 1985, Factors Involved and Lessons Learned, (Eds.) M. A. Cassaro and E. M. Romero, ASCE: 264-278.

18. Glauser, E.C. (1977), "The May 6, 1976 Friuli earthquakeAssessment and interpretation of building damage", Proceedings $6^{\text {th }}$ World Conference on Earthquake Engineering, New Delhi, 1: 279-288.

19. Hanson, R.D. and Degenkolb, H.J. (1969), "The Venezuela Earthquake: July 29, 1967", American Iron and Steel Institute, $N Y$.

20. Kasai, K. and Maison, B.F. (1991), "Observation of structural pounding damage from the 1989 Loma Prieta earthquake", Proceedings of the Sixth Canadian Conference on Earthquake Engineering, Toronto, Ontario: 735-742.

21. Wada, A., Shinozaki, Y. and N. Nakamura, N. (1984), "Collapse of building with expansion joints through collision caused by earthquake motion", $8^{\text {th }}$ World Conference on Earthquake Engineering: 855-862.

22. Kasai, K., Jeng, V., Patel, P.C. and Munshi, J.A. (1992), "Seismic pounding effects - survey and analysis", Proceedings of the $10^{\text {th }}$ World Conference on Earthquake Engineering, Spain, 7.

23. Mahin, S.A., Bertero, V.V., Chopra, A.K. and Collins, R.G. (1976), "Response of the Olive View Hospital main building during the San Fernando earthquake", Report No. EERC 76-22, Earthquake Engineering Research Center, University of California, Berkeley, CA, USA.

24. Carr, A.J. (1998), RUAUMOKO, Computer Program Library, Dept. of Civil Engineering, University of Canterbury, Christchurch, New Zealand.

25. Standards New Zealand, NZS 4203: 1992, "Code of Practice for General Structural Design Loadings for Buildings", Standards New Zealand, Wellington, New Zealand. 
26. Standards New Zealand, NZS 3101: Parts 1 and 2: 1995, "Concrete Structures Standard and Commentary", Standards New Zealand, Wellington, New Zealand, 1992.

27. Ford, C.R. (1926), "Earthquakes and Building Construction", Whitcombe and Tombs, Auckland, New Zealand.

28. Park, R. et al. (1995), "The Hyogo-ken Nanbu earthquake of 17 January 1995", Bulletin of the New Zealand National Society for Earthquake Engineering, 28(1): 1-98.

29. Kasai, K., Jeng, V. and Maison, B.F. (1990), "The significant effects of pounding-induced accelerations on building appurtenances", ATC-29, Applied Technology Council, Proceedings of the Seminar and Workshop on Seismic Design and Performance of Equipment and Nonstructural Elements in Buildings and Industrial Structures.

30. Malhotra, P.K., Huang, M.J. and Shakal, A.F. (1995), "Seismic interaction at separation joints of an instrumented concrete bridge", Earthquake Engineering and Structural Dynamics, 24: 1055-1067.

31. Tsai, H.-C. (1997), "Dynamic analysis of base-isolated shear beams bumping against stops", Earthquake Engineering and Structural Dynamics, 26: 515-528.

32. Rosenblueth, E. and Meli, R. (1986), "The 1985 earthquake: causes and effects in Mexico City", Concrete international ACI, 8: 23-36

33. Anagnostopoulos, S.A. (1996), "Building pounding reexamined: how serious a problem is it?" Proceedings of the $11^{\text {th }}$ World Conference on Earthquake Engineering., Acapulco, Mexico, Paper No. 2108.

34. Schmid, G. and Chouw, N. (1992), "Soil-structure interaction effects on structural pounding", Proceedings of the $10^{\text {th }}$ World Conference on.Earthquake Engineering, Spain, 3: 1651-1656

35. Paulay, T. and Priestley, M.J.N. (1992), "Seismic Design of Reinforced Concrete and Masonry Buildings", John Wiley and Sons, Inc., NY, USA.

36. Leibovich, E., Rutenberg, A., and Yankelevsky, D.Z. (1996), "On eccentric seismic pounding of symmetric buildings", Earthquake Engineering and Structural Dynamics, 25: 219-233.

37. Bertero, V.V. and Collins, R.G. (1973), "Investigation of the failures of the Olive View stairtowers during the San Fernando earthquake and implications on seismic design", EERC Report No. 73-26, Earthquake Engineering Research Center. University of California, Berkeley, CA, USA
38. Pender, M.J. (1995), "Earthquake resistant design of foundations", Proceedings of the Pacific Conference on Earthquake Engineering, Melbourne, Australia, 2:1-21.

39. Wolf, J.P. (1994), "Foundation Vibration Analysis Using Simple Physical Models", Prentice Hall, Englewood Cliffs, NJ, USA.

40. Gazetas, G. (1983), "Analysis of machine foundation vibrations: state-of-the-art review", Soil Dynamics and Earthquake Engineering, 2(1): 2-42.

41. Warburton, G.B., Richardson, J.D. and Webster, J.J. (1971), "Forced vibrations of two masses on an elastic half-space", Journal of Applied Mechanics, ASME: 148156.

42. Roesset, J.M. and Gonzalez, J.J (1977), "Dynamic interaction between adjacent structures", Proceedings of Dynamical Methods in Soil and Rock Mechanics, Karlsruhe, Germany, 1: 127-166.

43. Imamura, A., Ishizaki, M., Watanabe, T., and Motossaka, M. (1992), "Seismic response characteristics of embedded structures considering cross interaction", Proceedings of the $10^{\text {th }}$ World Conference on Earthquake Engineering, Spain, 3: 1719-1724.

44. Kobori, T. Minai, R. and Kusakabe, K. (1977), "Dynamical cross-interaction between two foundations", Proceedings of the $6^{\text {th }}$ World Conference on Earthquake Engineering, New Delhi, 2: 1484-1489.

45. Shohara, R., Kurosawa, I., Shinozaki, Y. and D. Sakamoto (1992), "Tests on dynamic interaction between foundations", Proceedings of the $10^{\text {th }}$ World Conference on Earthquake Engineering, Spain, 3:1879-1884.

46. Mulliken, J.S. and Karabalis, D.L. (1998), "Discrete model for dynamic through-the-soil coupling of 3-d foundations and structures", Earthquake Engineering and Structural Dynamics, 27: 687-710.

47. Richart, F.E., Hall, J.R. and Woods, R.D. (1970), "Vibrations of Soils and Foundations", Prentice-Hall, Englewood Cliffs, NJ, USA.

48. Wolf, J.P. (1988), "Soil-Structure Interaction in Time Domain", Prentice-Hall, Englewood, Cliffs, NJ, USA

49. Jury, R.D. (1978), "Seismic Load Demands on Columns of Multi-Storey Frames", M.E. Report 78-12, Dept. of Civil Engineering, University of Canterbury, Christchurch, New Zealand.

50. Otani, S. (1974), "SAKE, a Computer Program for Inelastic Response of R/C Frames to Earthquakes", Report UILU-Eng-74-2029, Civil Engineering Studies, University of Illinois at Urbana-Champaign, USA. 
51. Leger, P., and Dussault, S. (1992), "Seismic-energy dissipation in MDOF structures", Journal of Structural Engineering, 118(5): 1251-1269.

52. Maison, B.F., and Neuss, C.F., "SUPER-ETABS: An Enhanced Version Of ETABS Program", Technical Report to the National Science Foundation, J.G.Bouwkamp Inc., Darmstadt, Germany.

53. Papadrakakis, M., and Mouzakis, H.P. (1995), "Earthquake simulator testing of pounding between adjacent buildings", Earthquake Engineering and Structural Dynamics, 24: 811-834,

54. Sinclair, K.M. (1993), "The Response of Multi-Storey Frames to Seismic Pounding", ME Report, Department of Civil Engineering, University of Canterbury; Christchurch, New Zealand.

55. Goldsmith, W. (1960), "Impact: The Theory and Physical Behaviour of Colliding Solids", Edward Arnold Ltd., London.

56. Rahman, A.R. (1999), "Seismic Pounding of Adjacent Multiple-Storey Buildings Considering Soil-Structure Interaction and Through-Soil Coupling", PhD Thesis, Department of Civil Engineering, University of Canterbury; Christchurch, New Zealand. 